\title{
حكم الأطعمة المعدلة بتقنية النانو تكنولوجي
}

\author{
رجاء محمد محفوظ مطلق \\ أستاذ مساعد- جامعة سيئون- اليمن \\ dr.motlaq3@gmail.com
}

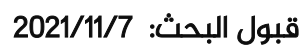

مراجعة البحث: 10/20/

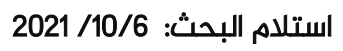




\title{
حكم الأطعمة المعدلة بتقنية النانو تكنولوجي
}

\author{
رجاء محمد محفوظ مطلق

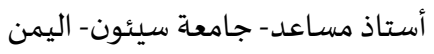 \\ dr.motlaq3@gmail.com
}

DOI: https://doi.org/10.31559/SIS2021.6.3.3 2021/11/7 استلام البحث: 2021/10/6 مراجعة البحث: 2021/10/20 قبول البحث

تتناول هذه الدراسة الأطعمة المعالجة بتقنية النانو تكنولوجي، التي تعدُّ من النوازل المفتقرة إلى بيان موقف الشريعة الإسلامية،

وهي الأطعمة التي تم التحكم في ترتيب الذرات والجزيئات النانومترية، المكوّنة بواسطة تقنية النانو تكنولوجي؛ للحصيول على أطعمة

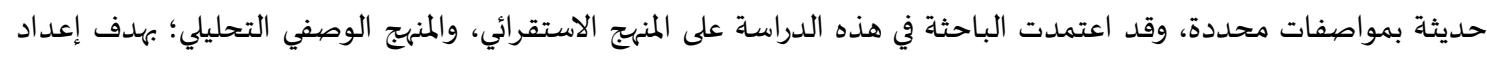

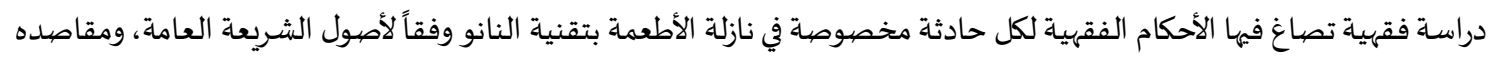

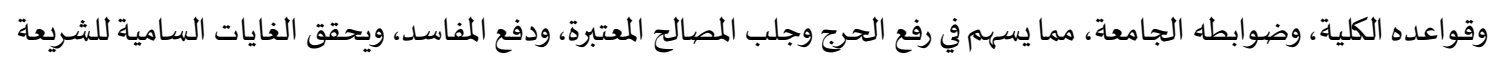

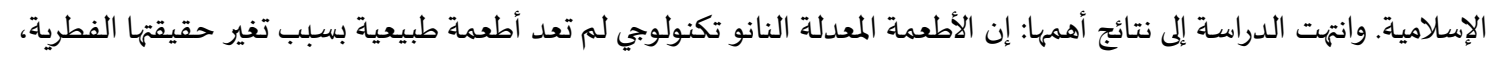

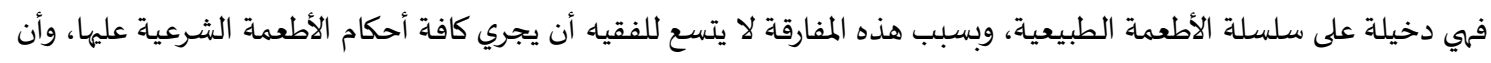
تعاطي الأطعمة المعدلة بالنانو تكنولوجي بوصفها غذاء أو دواء، يتوقف على النظر الفقهي في حجم المنافع والمفاسد التي تؤول إلهها هذه

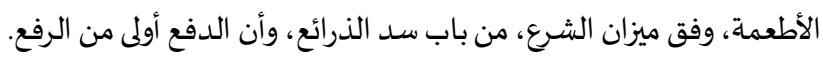
الكلمات المفتاحية: حكم الأطعمة؛؛ تقنية النانوتكنولوجي؛ الأطعمة النانوية.

الحمد لله الرحمن الرحيم حمدًا كثيراً طيباً مباركاً فيه، وأشهد أن لا إله إلا الله وحده لا شريك له، وأشهد أن محمداً عبده ورسوله

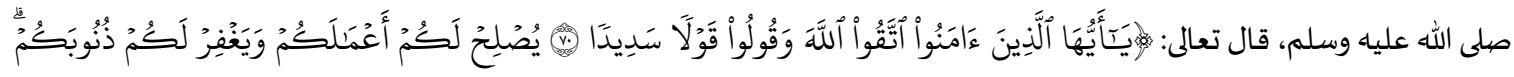

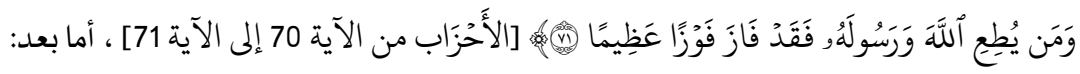

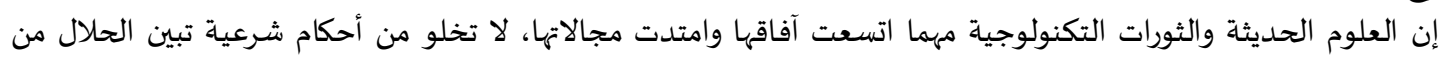
الحرام؛ ليكون المسلم على بصيرة في معيشته ومعاملاته، فكان من رحمة الله وحكمته أن جعل الشريعة الإسلام خاتمة الشرائع، صالحة

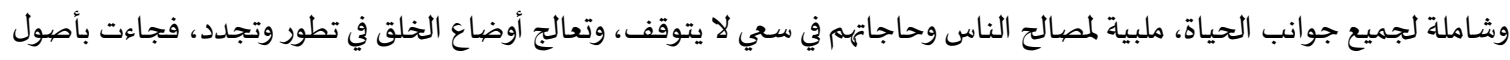

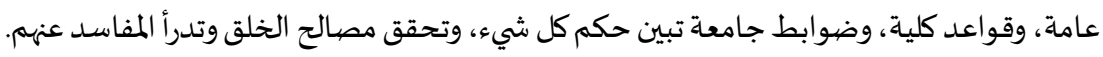

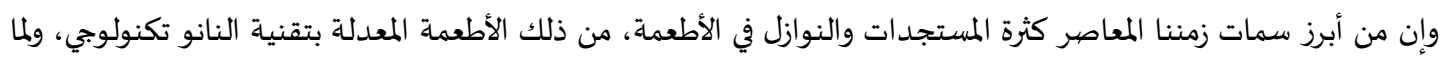

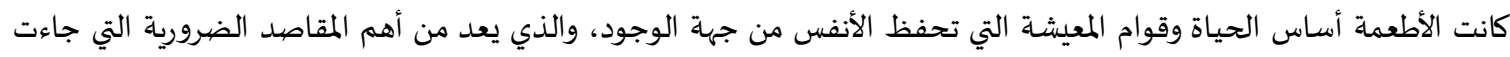

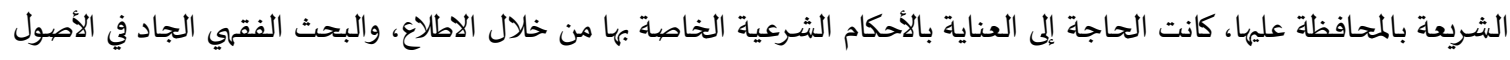

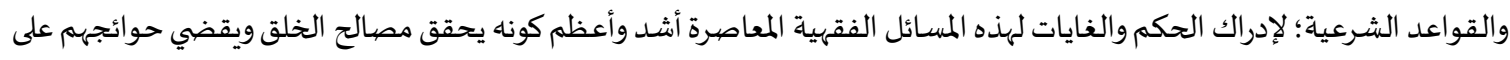




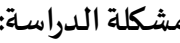

تتحدد مشكلة الدراسـة في الإجابة عن السؤال الرئيس الآتي:

ما حكم الأطعمة المعدلة بتقنية النانو تكنولوجي؟

$$
\begin{aligned}
& \text { ويتفرع عناه الأسئلة الآتية: }
\end{aligned}
$$

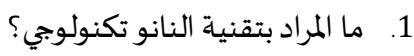

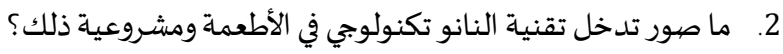

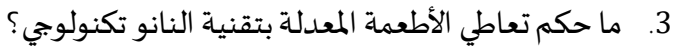

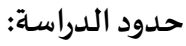

هذه الدراسة تتمحور حول حدود موضوعية وهي الأطعمة المعدلة بتقنية النانو تكنولوجي، وما ارتبط بذلك من موضوعات تبرز

صورة المسألة وتحقق غايات البحث وأهد افهـ.

$$
\text { أسباب اختيار موضهوع الدراسة: }
$$

أولاً: الرغبة في الإجابة عن تساؤيار موضوعاتي الخاصة بتقنية النانو تكنولوجي وإشباع معارفي الفقهية في نوازل الأطعمة المعدلة بتقنية النانو تكنولوجي. ثانياً: تطوير القدرات البحثية من خلال تطبيق المعارف النظرية للنوازل بدراسة تطبيقية تعنى بالأطعمة المعدلة بتقنية النانو تكنولوجي. ثالثأ: توافر إمكانات معرفية وبحثية شحذت همتي وعززت رغبتي لتناول موضورع الأطعمة المعدلة بالنانو تكنولوجي. أهمية الدراسـة:

تظهر أهمية هذه الدراسة من خلال الأمور الآتية: أولاً: قيمة البحث علمياً وعملياً؛ إذ يسلط الضوء على مستجدات علم النانو تكنولوجي الذي اختلط بكل تفصيلات معاش الناس، ولامس حاجتهم، من ذلك أصل وجود الغذاء والداوء. ثانياً: قدرة البحث على إيجاد إجابات شافية دلتساؤلات أرقت العقل عن قدرة علم النانو تكنولوجي في إيجاد أطعمة متغيرة الجزيئات

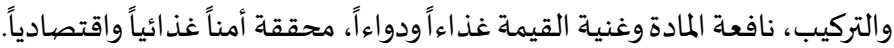
ثالثاً: إثراء البحوث العلمية الشرعية بمواضيع معاصرة تمالج قضئهايا النوازل في الأطعمة وتجمع بين علمين مهمين أحدهما شرعي وهو علم الفقه، والآخر من علوم البيولوجيا التطبيقية في مجال تكنولوجيا النانو. بهوبئ.

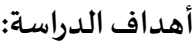

تسعى هذه الدراسة إلى تحقيق ما يأتي: 1 1 . بيان معنى الأطعمة المعالجة بتقنية النانو تكنولوبي. 2. معرفة مشروعية علم النانو تكنولوجي. 3. معرفة حكم إجراء التعديلات بتقنية النانو تكنولوبي على الأطعمة.

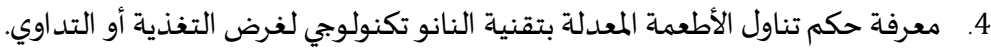

الدراسات السابقة: بعد البحث والاستقراء تبين وجود بعض الدراسات والبحوث السابقة والتي لها صلة بموضيوع البحث، وهي كالآتي: دراسة الحوشاني (2021) فقه التوقع ومآلات تقنية النانو، تطرقت فياه إلى أقوال الفقهاء في فقه التوقع وشروطه ومراحل النظر

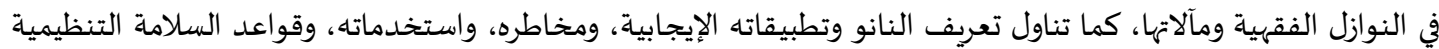
لهذه التقنية، وهو جهد مبارك تشكر عليه الباحثة الكريمة، إلا أن الدراسة بقيت بمنأى عن جانب التقعيد الفقهي لتقنية النانو

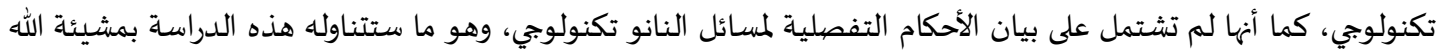

دراسة الطعيمات (2013) تكنولوجيا النانو من جهة نظر شرعية، وتناولت هذه الدراسة تعريف النانو والآثار السلببية

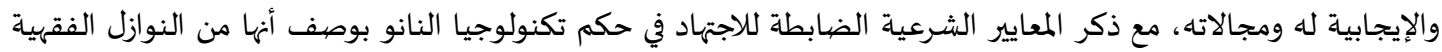


العامة، وهو جهد مبارك وإضافة متميزة للمكتبة الإسلامياة، إلا أن الدراسة بقيت عامة من جانب بيان حكم تقنية النانو، وهي

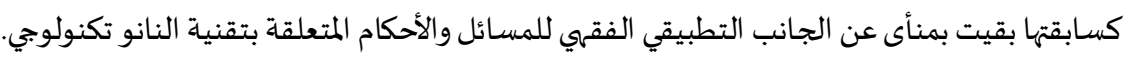

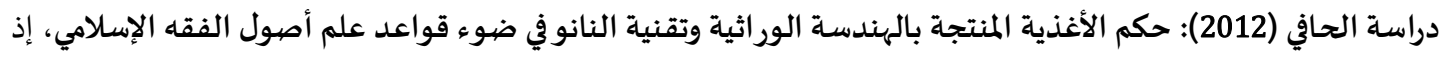

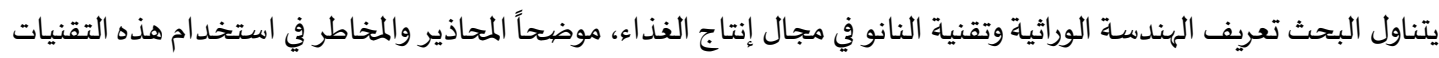

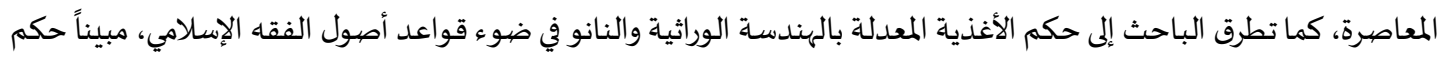

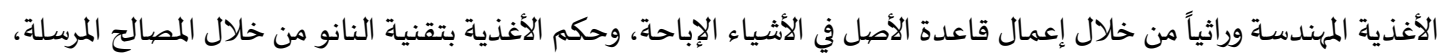

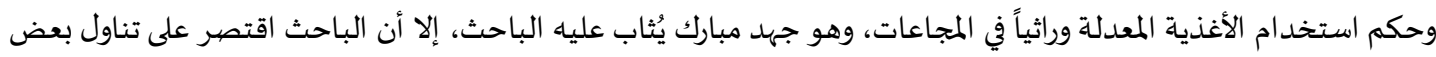

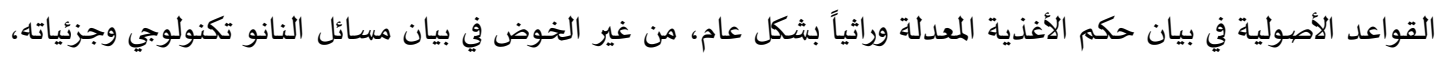

والتقعيد الفقهي لها.

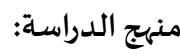

تبعت الباحثة في هذا البحث المنهج الاستقرائي والوصفي التحليلي من خلال استقراء المسائل الفقهية المتعلقة بالأطعمة المعدلة

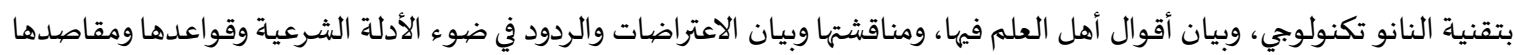
الشرعية.

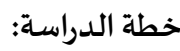

اشتمل هذا البحث على مقدمة ومبحثين وخاتمة:

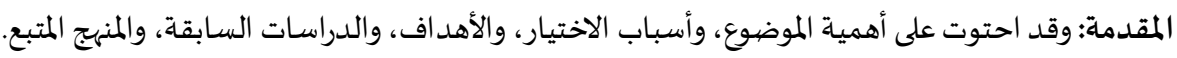

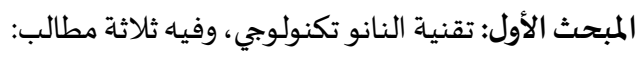

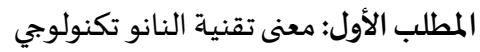

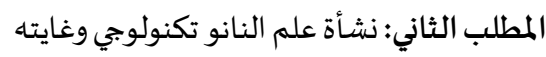
المطلب الثالث: مشروعية علم النانو تكنولوجي. المبحث الثاني: حكم التدخلات في الأطعمة المعدلة بتقنية النانو تكنولوبية المناني، وفيه ثلاثة مطالب: المطلب الأول: مشروعية إجراء التعديلات على الأطعمة بتقنية النانو تكنولوجيا.

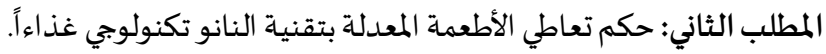

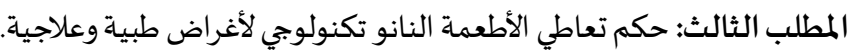
ثم الخاتمة ملخصية أهم النتائج والتوصيات. المبحث الأول: تقنية النانو تكنولوجي، وفيه ثلاثة مطالب:

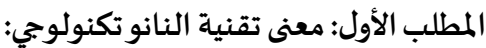

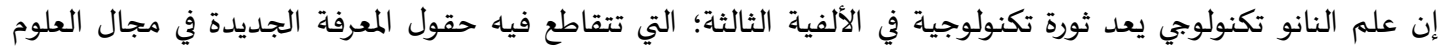

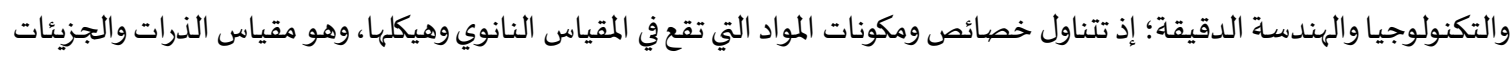

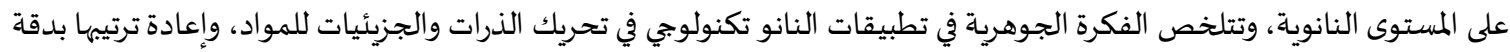

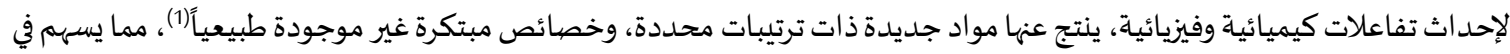

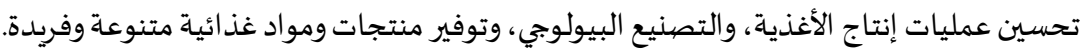

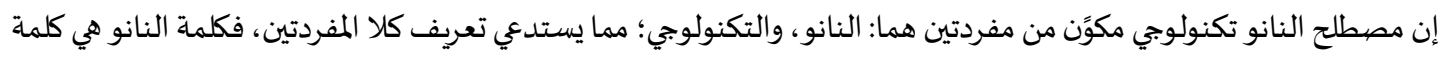

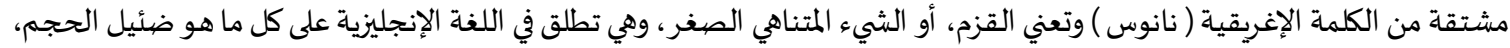

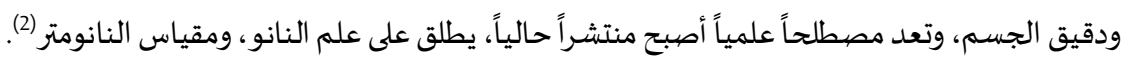


وأما كلمة التكنولوجيا فهي كلمة إغريقية الأصل، مكونة من مفردتين، هما: (تكنو) تعني الحرفة أو المهارة، و(لوجيا) ويراد بها الدرس،

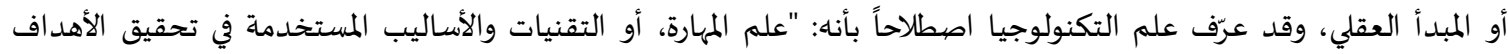

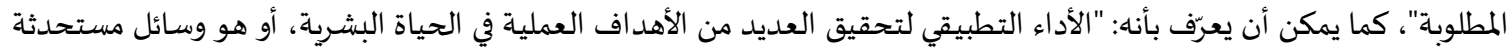

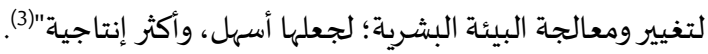
وقد عرف النانو تكنولوبي اصطلاحاُ (Nano Technology) بأنه:" تطبيق علمي يتولى إنتاج الأشياء عبر تجميعها من مكوناتها

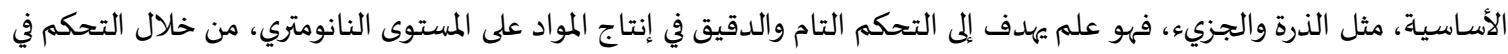

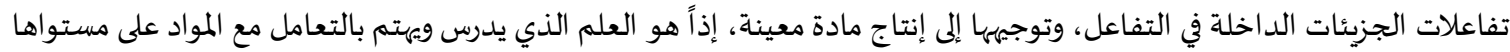

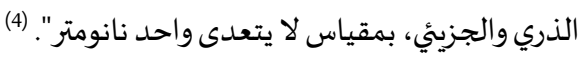

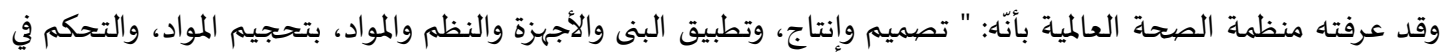

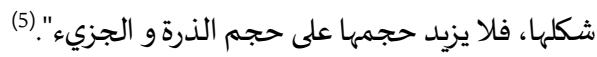

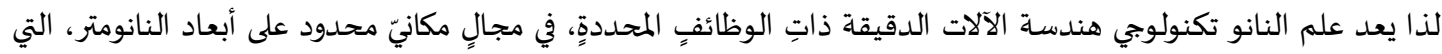

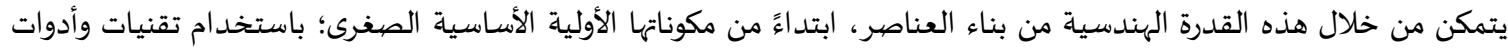

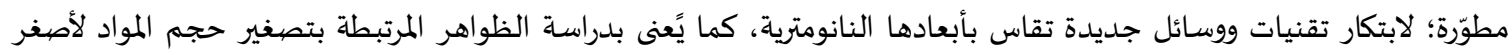

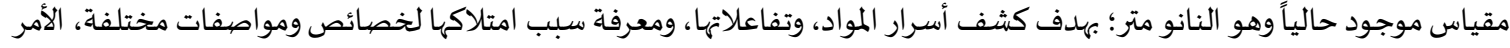

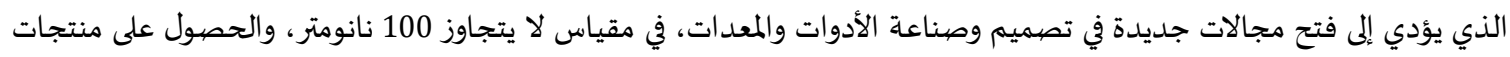

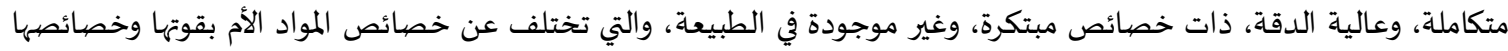

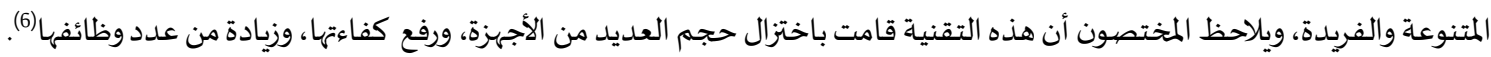

المطلب الثاني: نشأة علم النانو تكنولوجي وغايته:

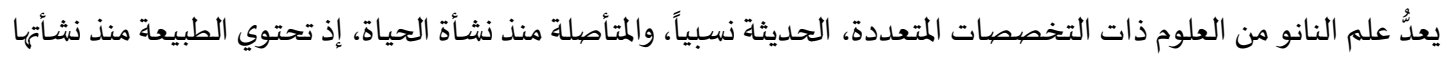

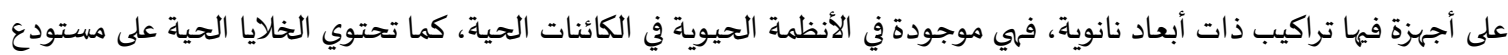

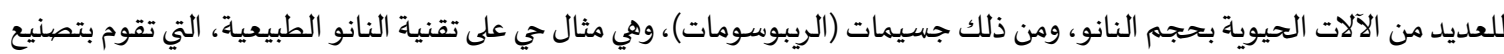

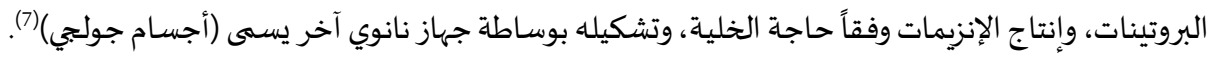

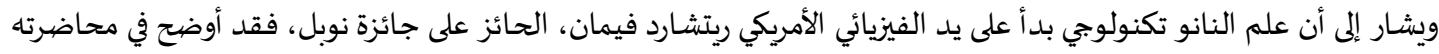

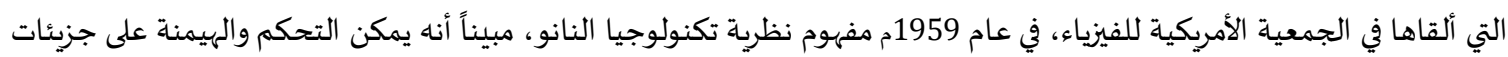

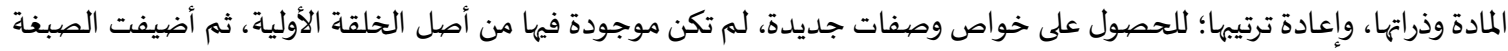

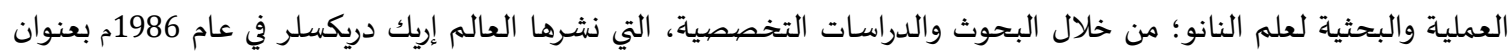

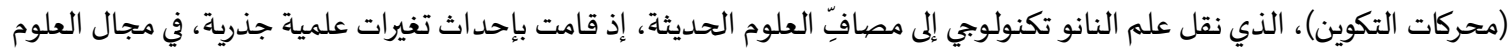

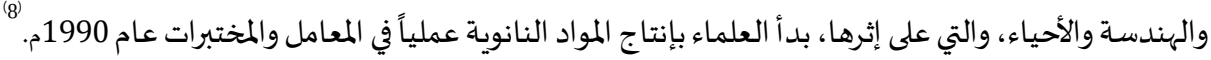

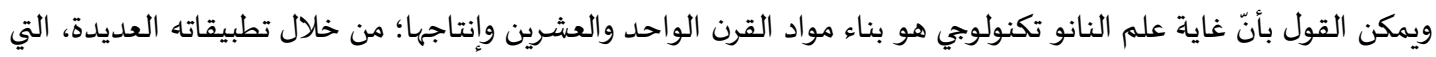

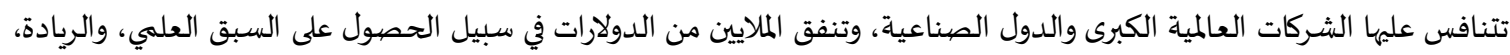

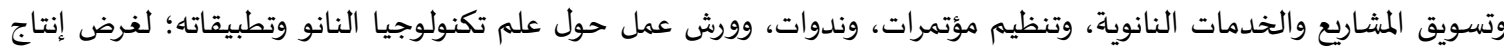

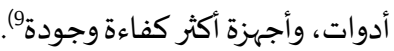

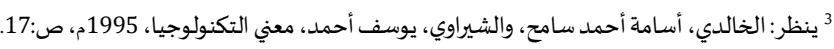

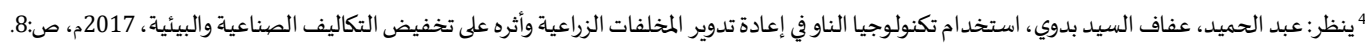

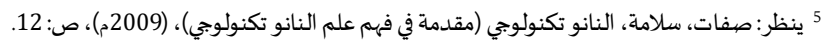

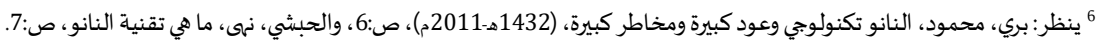

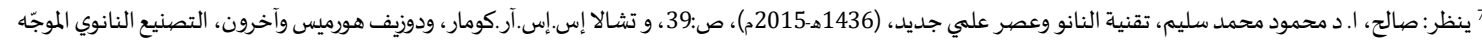

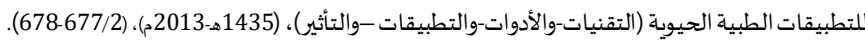

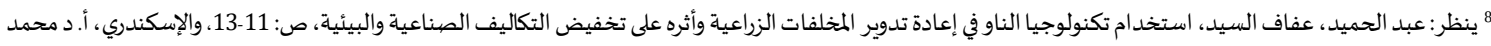

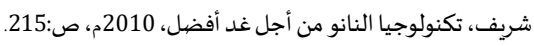

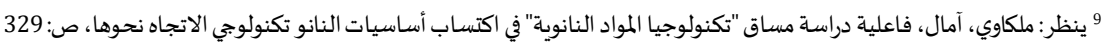




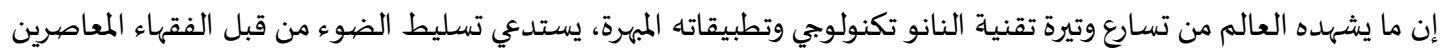

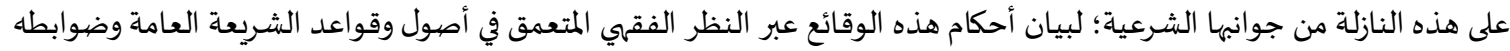

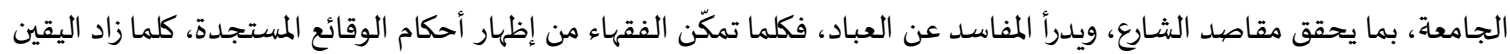

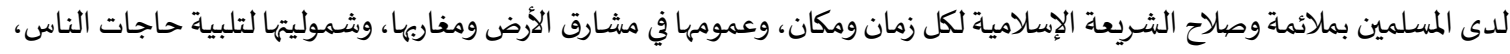

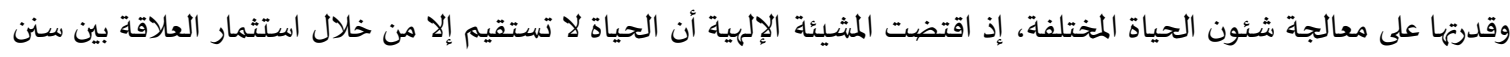

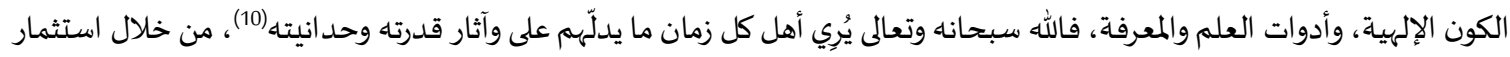

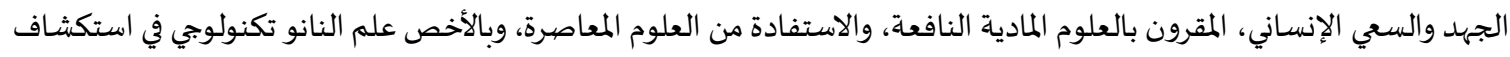

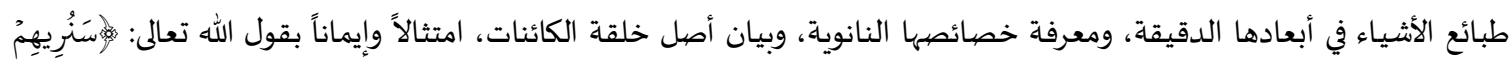

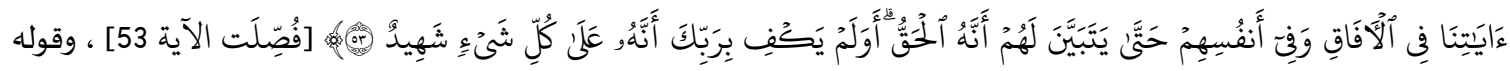

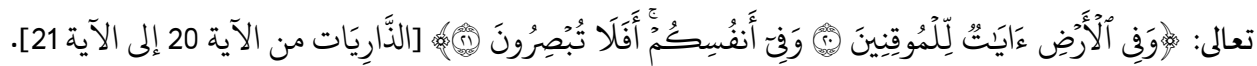

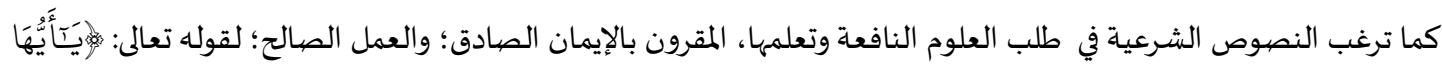

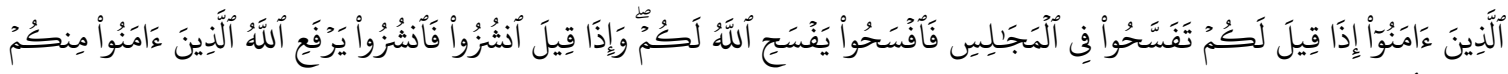

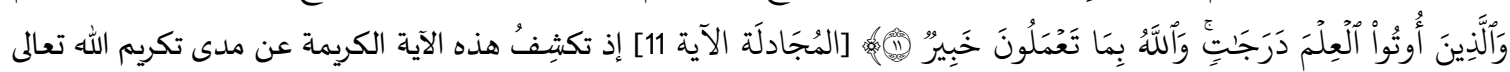

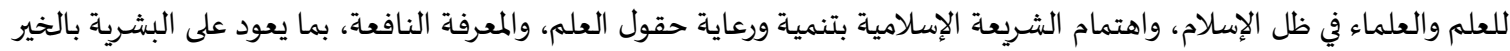

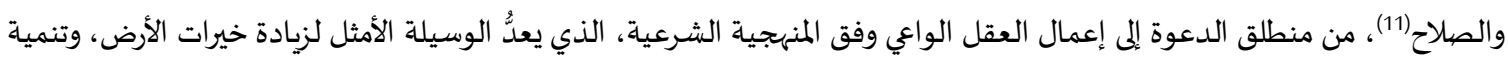
آفاقها، وتوسيع مجالات عطاءها(12)، لذلك توجاء العلماء والباحثين للاستفادة من تقنية النانو تكنولوجي، وتسخيرها في تنمية مصادر

الثروات الطبيعية في الكون، بما يحقق مصالح الخلق الضرورية والحاجية والتحسينية، ويلبي رغباتهم في ظل الشربعة السمحاء.

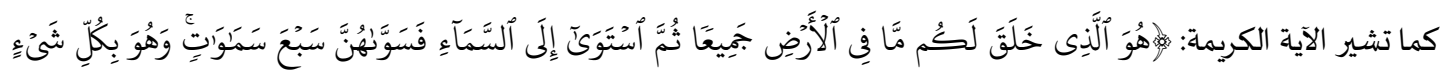

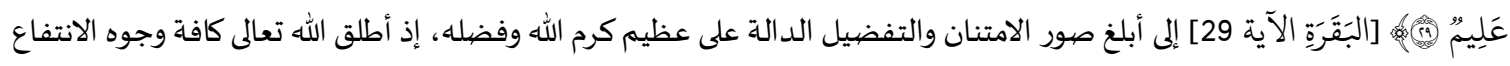

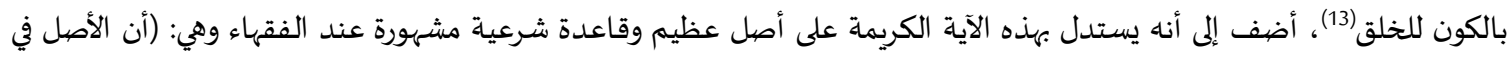

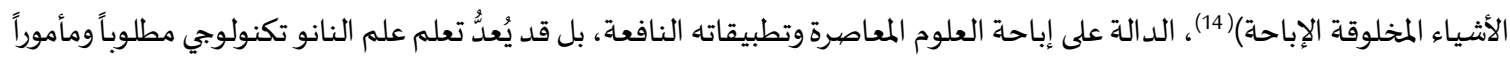

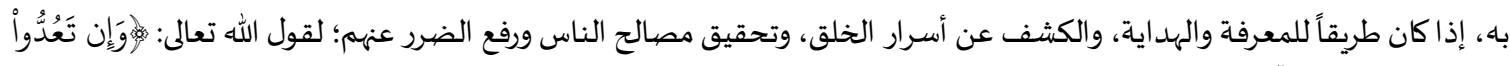

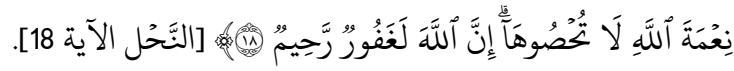

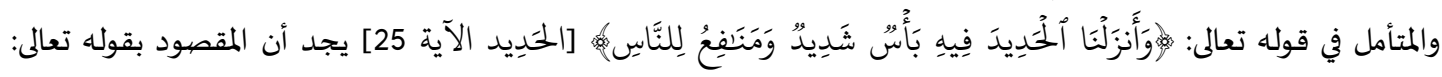

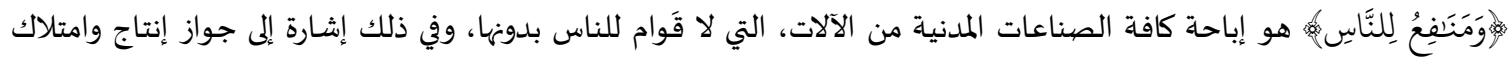

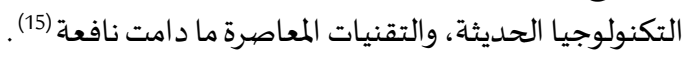
ومن خلال تتبع الأحاديث النبوية الشريفة، نجدها زاخرة بالدلالات على مشروعية تعلم كل ما ينفع الناس في دينهم ودنياهم، فعن

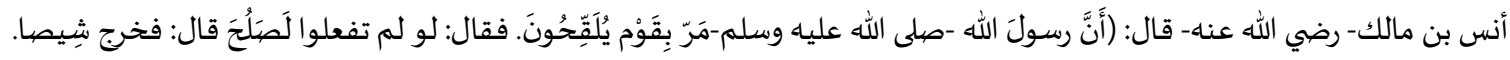

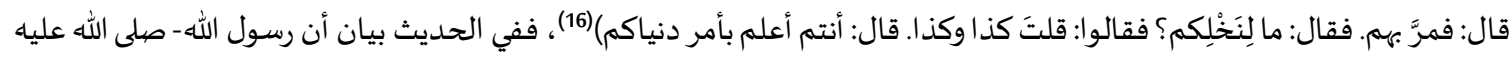

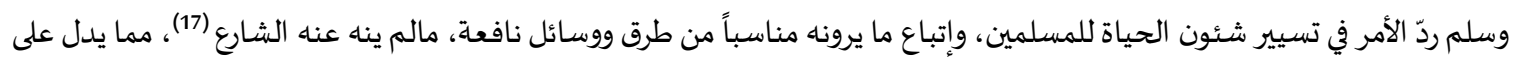

10 ينظر: ابن كثير، تفسير القرآن العظيم، (175/7)

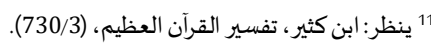

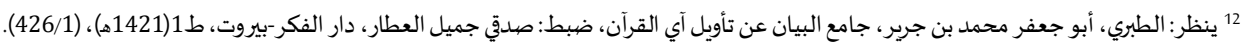

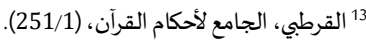

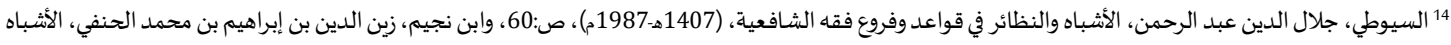

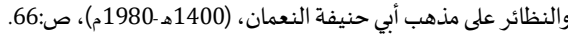

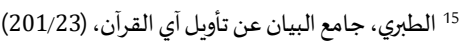

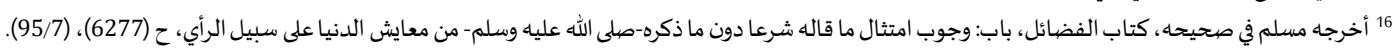

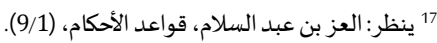
المجلة الدولية للدراسات الإسلامية المتخصصة- المجلد6، العدد3- 2021، ص: 182- 197 
جواز الانتفاع بكل مظاهر التقدم العلمي، في كافة صوره ومجالاته المباحة، ومن ضمن ذلك تطبيقات علم النانو تكنولوجي، التي تعد إحدى تطبيقات إدارة شئون الحياة بما يعود بالنفع على الخلق.

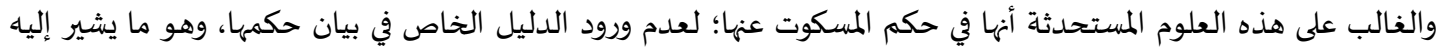

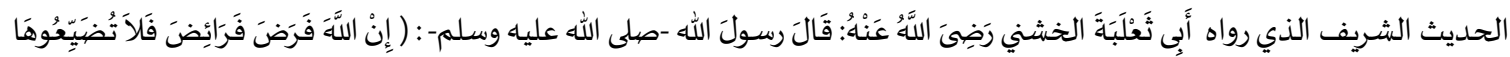

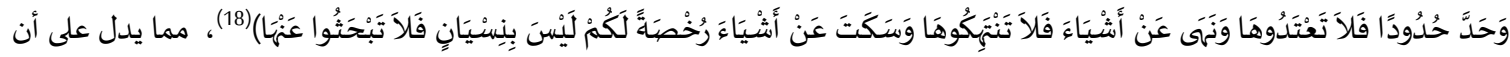

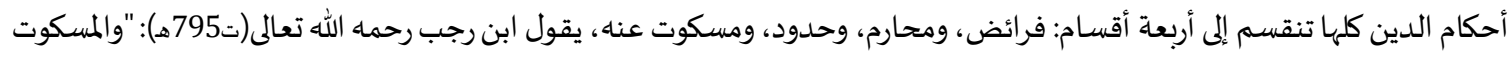

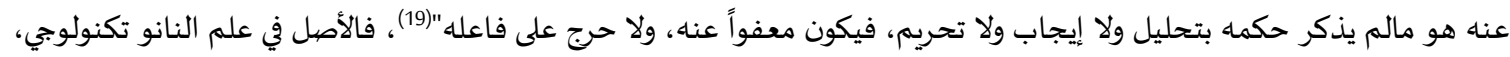

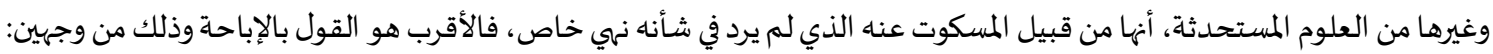

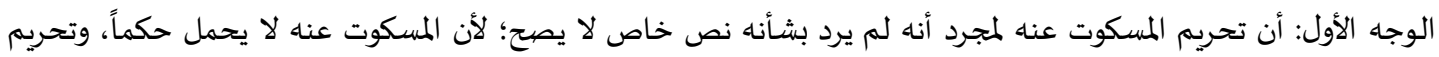

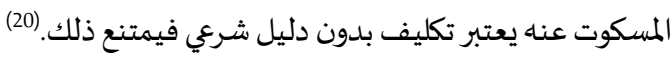

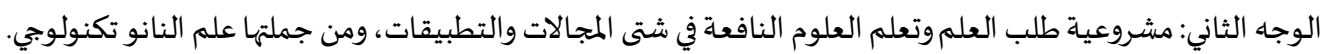

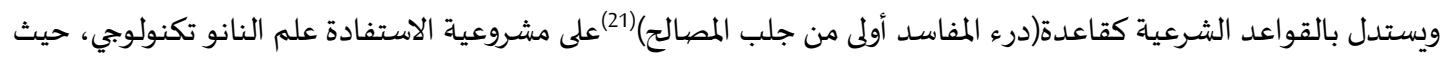

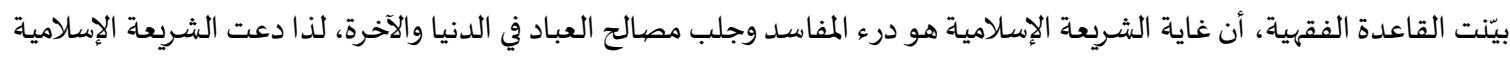

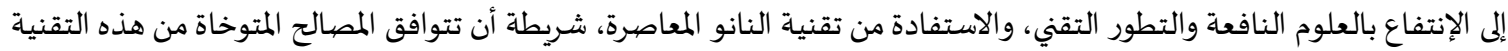

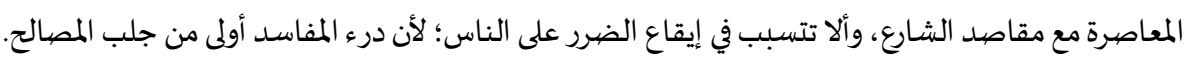

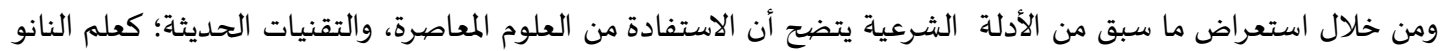

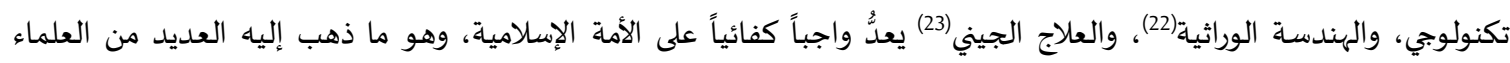

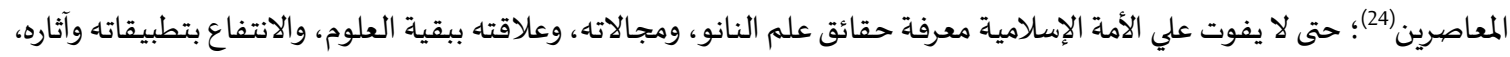

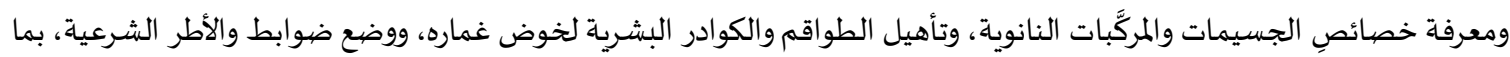
يعود بالنفع على البشرية جمعاء، ويحول دون العبث بالمخزون الوراثي للكائنات الحية، أو يؤدي إلى تغيير خلقة اللهاتها

\section{المبحث الثاني: حكم التدخلات في الأطعمة المعدلة بتقنية النانو تكنولوجي، وفيه ثلاثة مطالب:}

المطلب الأول: مشروعية إجراء التعديلات على الأطعمة بتنقية النانو تكنولوجي:

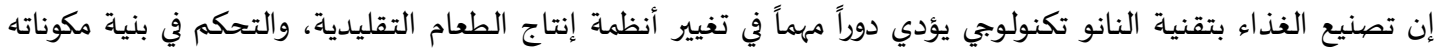

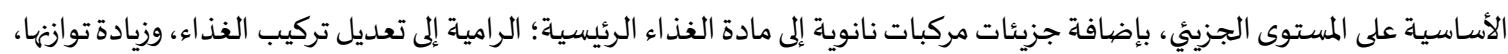
وتكاملها الغذائي والصيحي.

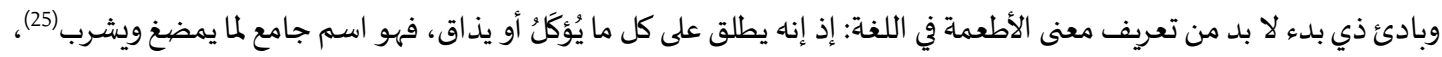

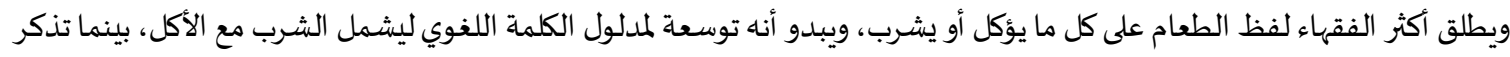

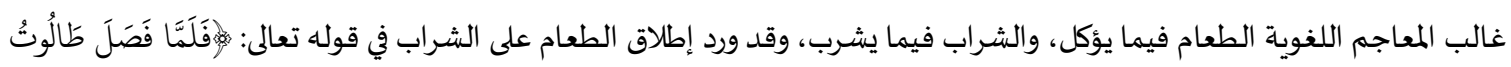

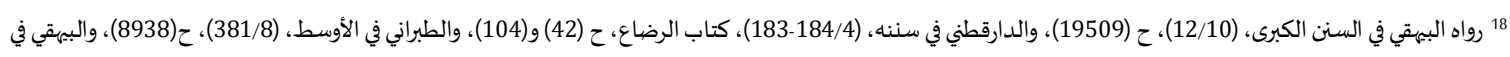

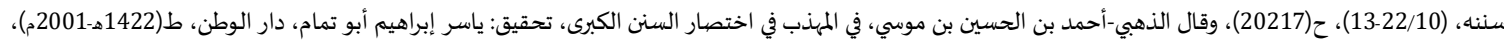
(2976/8) : "موقوف ومنقطع، لم يلق مكحول أبا ثعلبة".

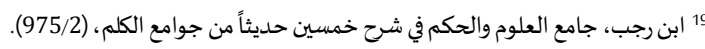

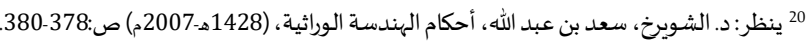

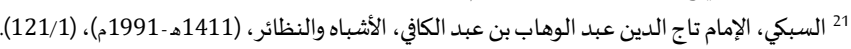

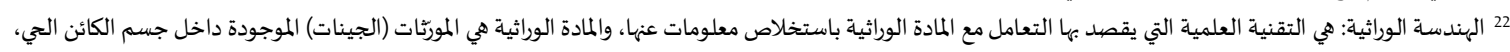

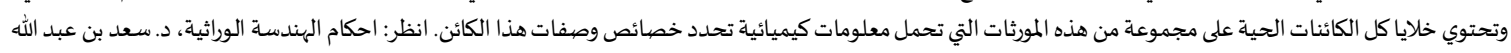

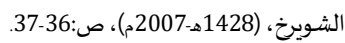

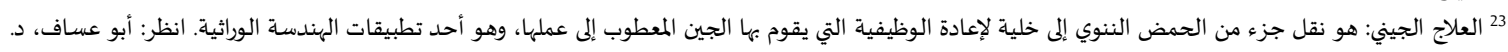

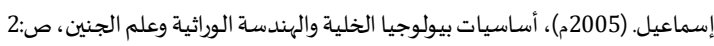

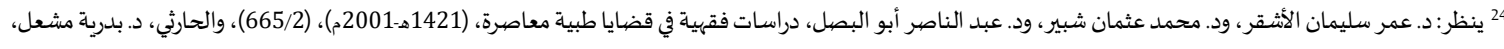

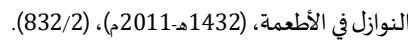
25 ينظر: ابن منظور، لسان العرب، محمد بن مكرم بن منظور الأفريقي المصري، (1414هـ)، مادة(طعم)، (363/12). 


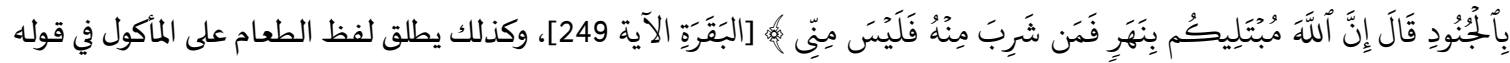

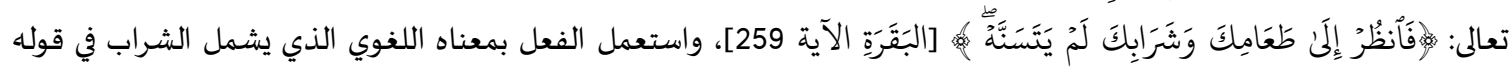

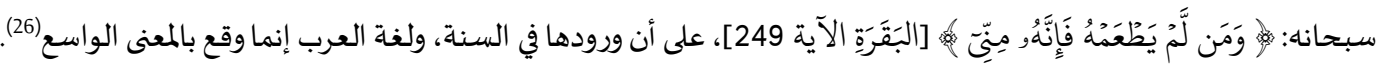

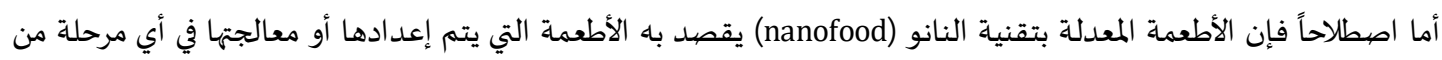

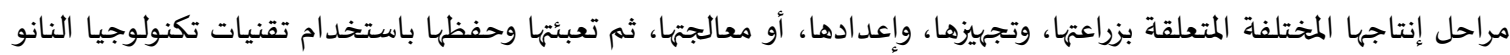

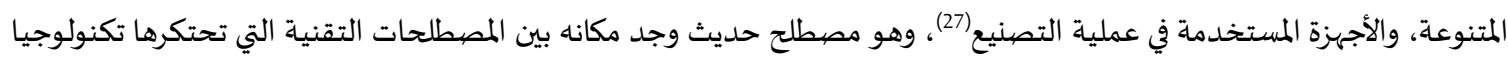

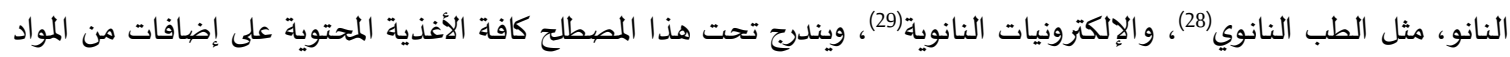

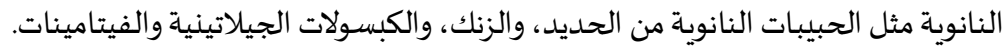

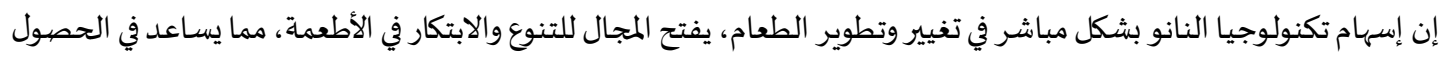

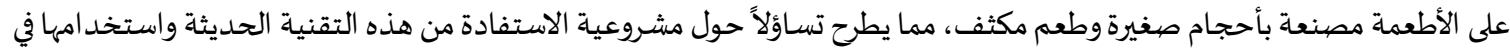

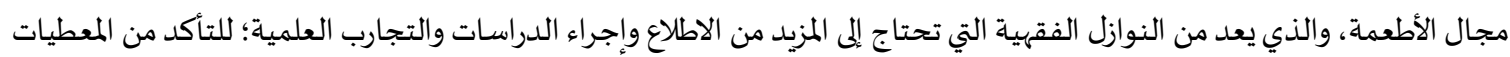

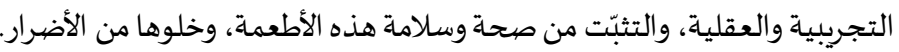

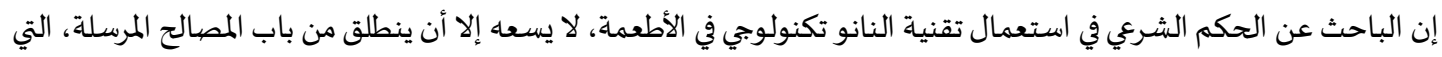

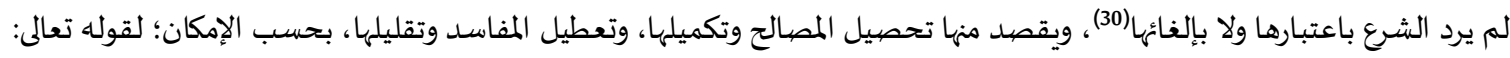

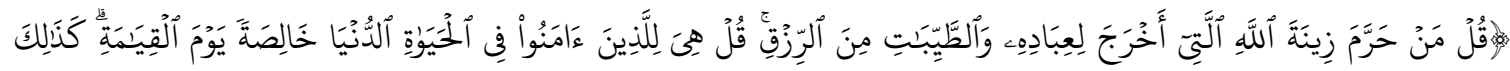

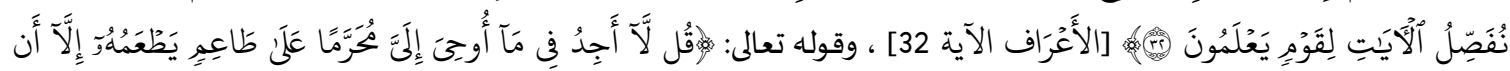

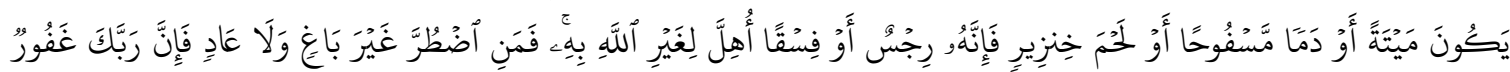

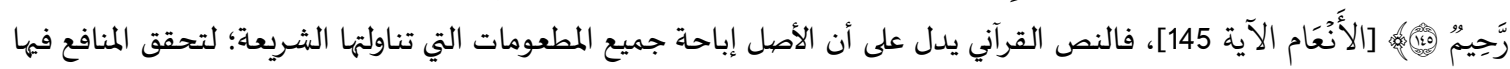

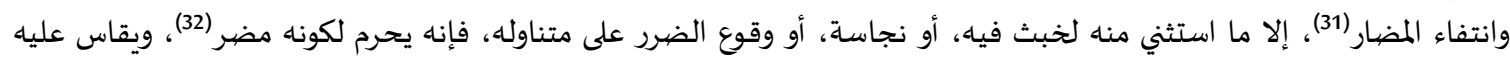

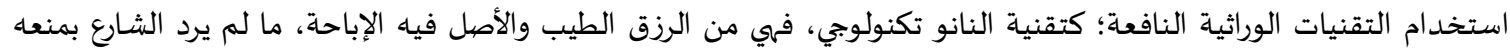

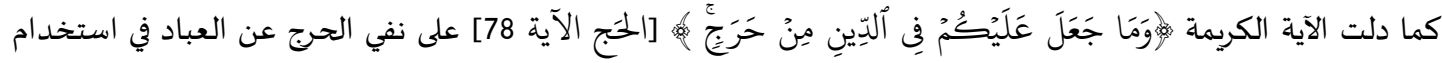

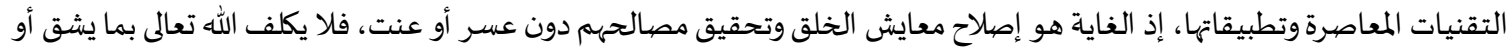

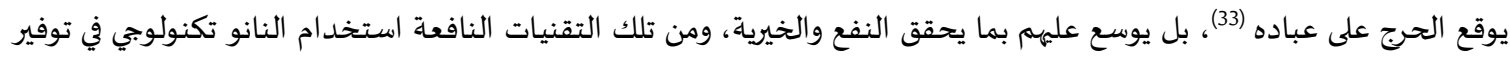

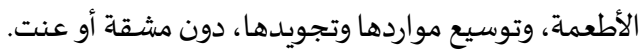

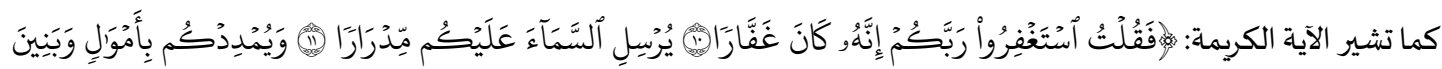

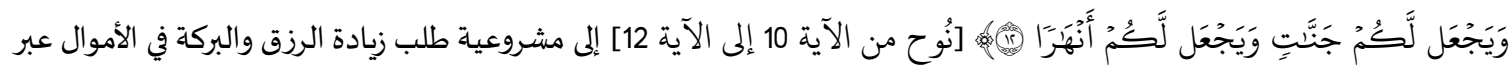

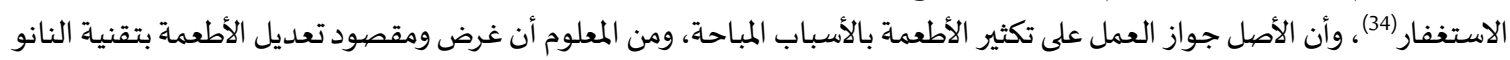

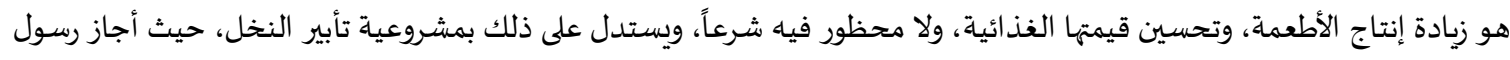

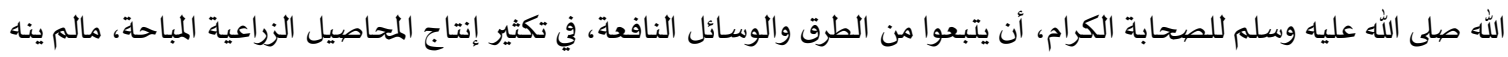

(423/1).

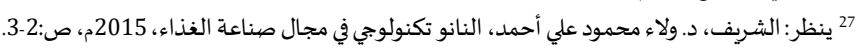

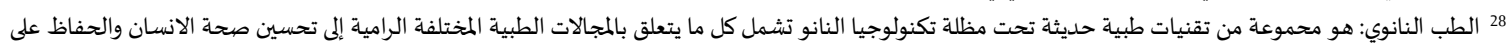

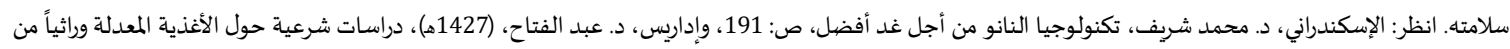
منظور إسلامي، ص: 23. 29 الإلكترونيات النانوية: هي عبارة عن شرائح إلكترونية جديدة بخواص فريدة من مواد متناهية الصغر يمكن أن تعمل كترانزستور لصناعة أجيال من معالجات الحاسبات السربعة

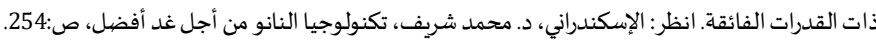

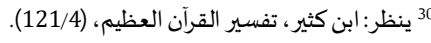

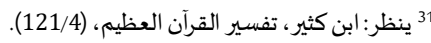

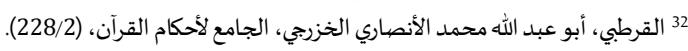
33 ينظر: السيوطي، الأشباه والنظائر، (35/1). 34 ينظر: المصدر السابق، (303/18). 


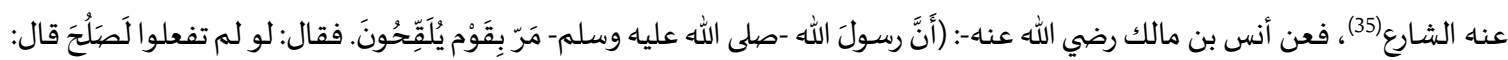

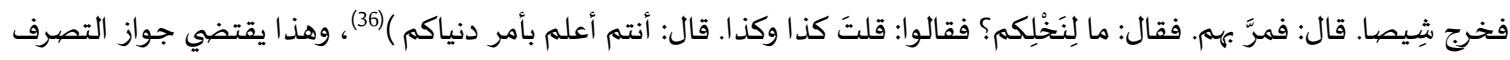

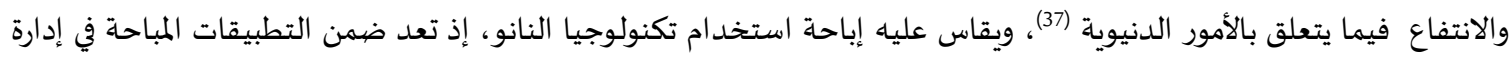

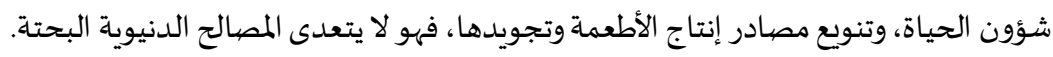

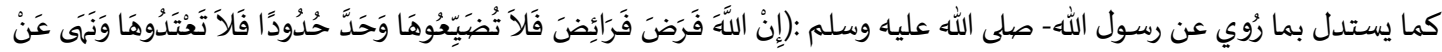

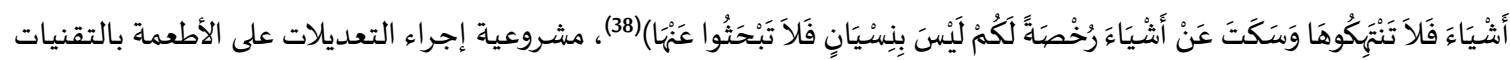

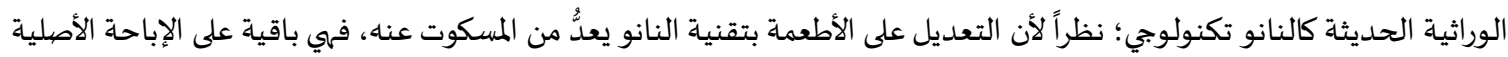

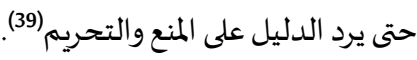

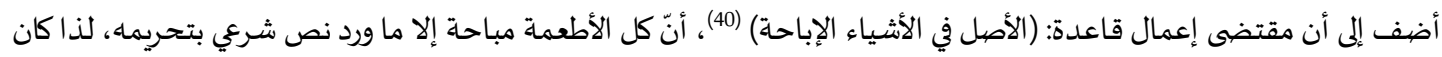

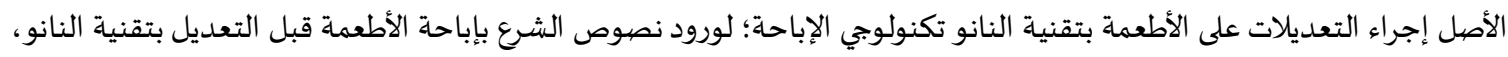

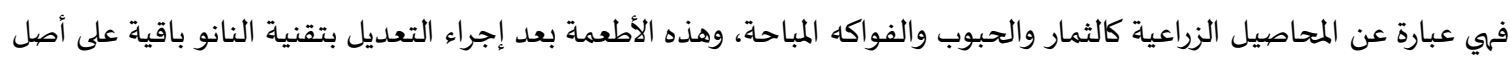

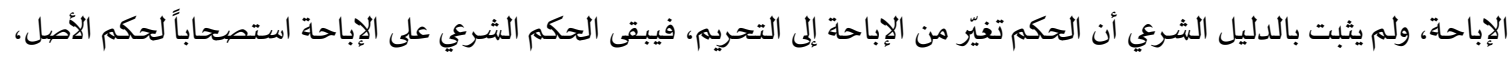

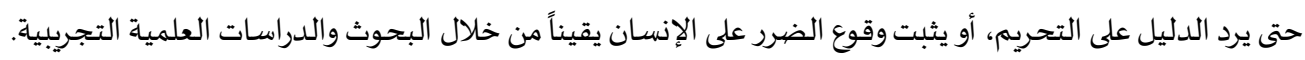

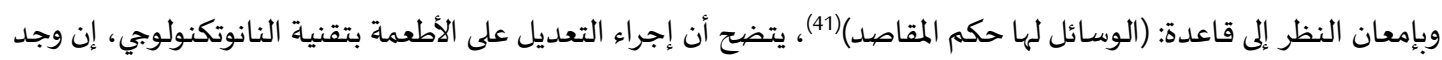

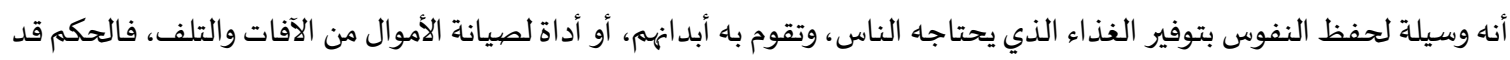

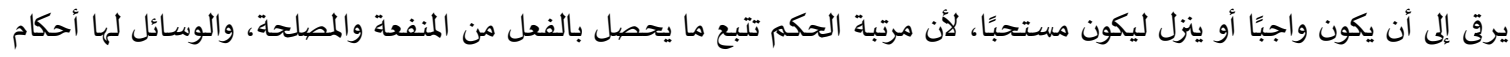
المقاصد.

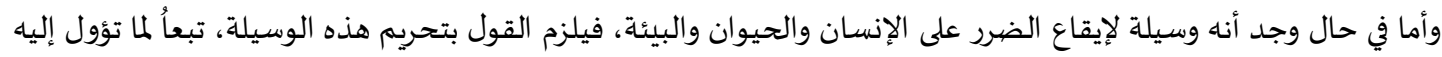

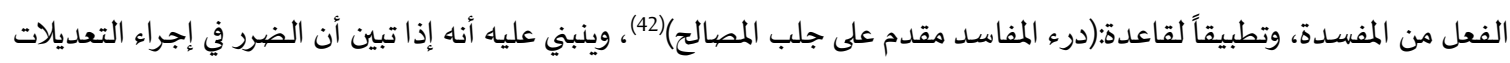

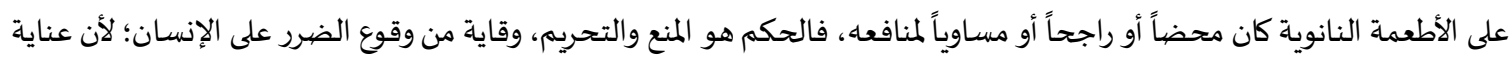

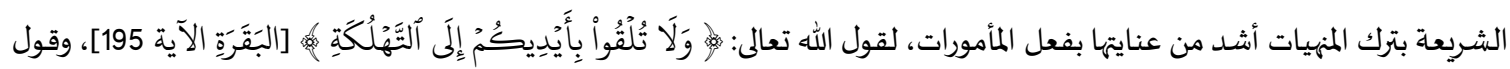
رسول الله صلى الله عليه وسلم: (لا ضرر ولا ضهرار) (43).

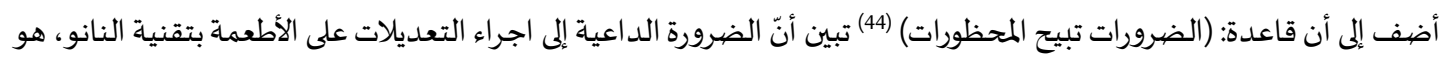

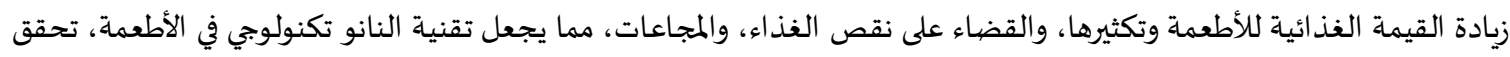

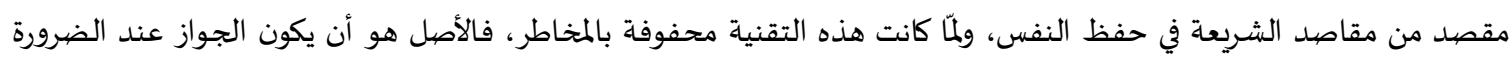

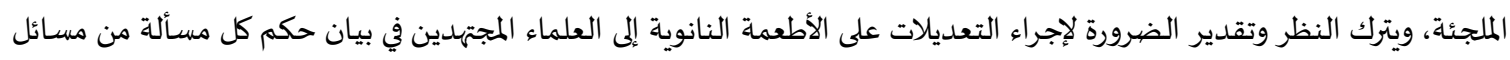

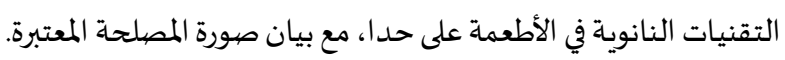

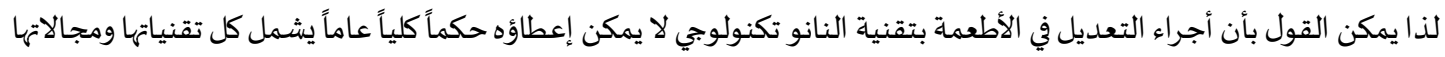

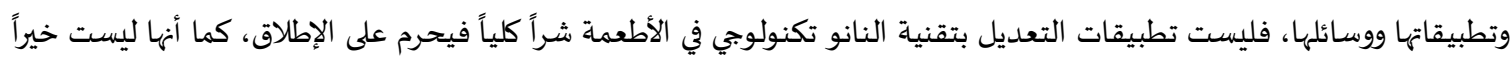

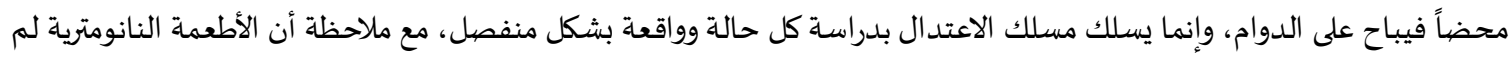

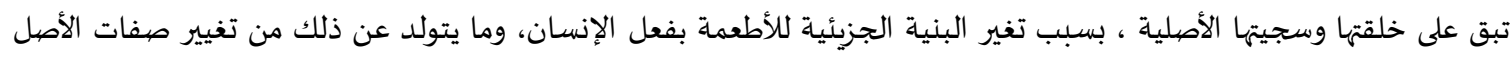

(35 العز بن عبد السلام، قواعد الأحكام، (9/1).

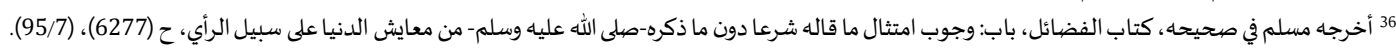

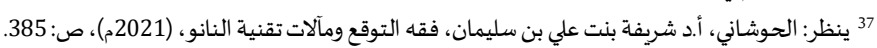

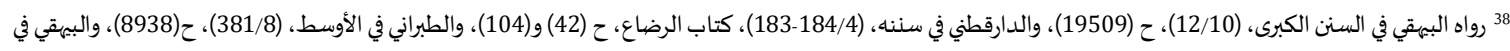

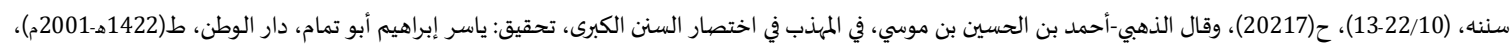

(2976/8): "موقوف ومنقطع، لم يلق مكحول أبا ثعلبة".

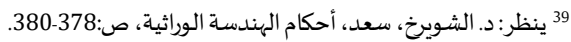
(60) ابن نجيم، الأشباه والنظائر، (66/1).

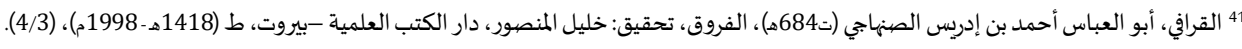
(32 السبكي، الأشباه والنظائر، (121/1).

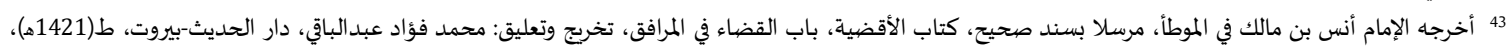

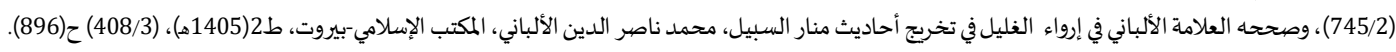

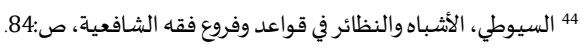


كالطعم أو اللون أو الرائحة، فلا بد من توخي الحذر للمضار والمفاسد المتوقعة، وعدم التساهل في أمرها، من باب سد الذرائع؛ لاحتمال

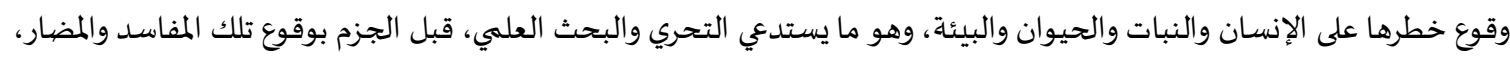

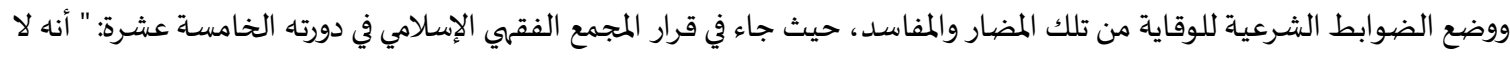

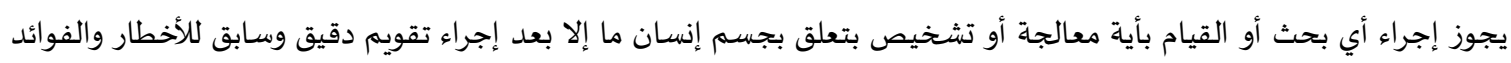

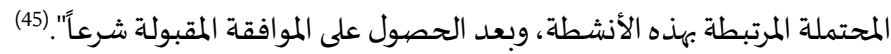

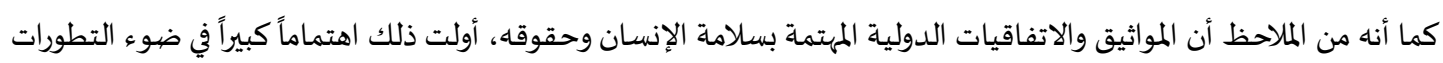

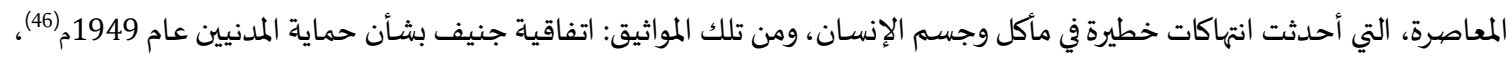

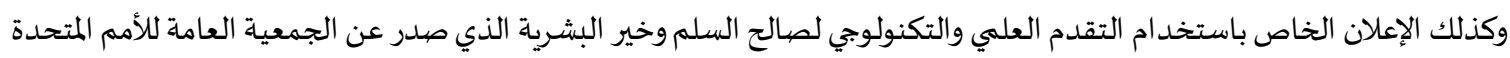

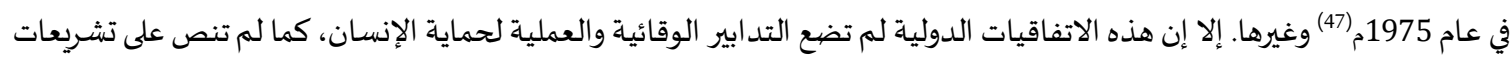

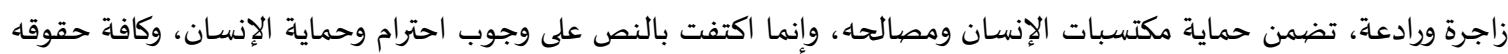

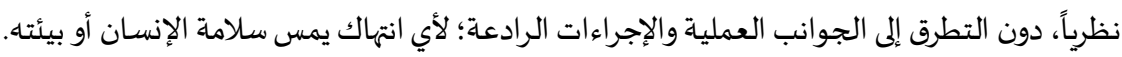

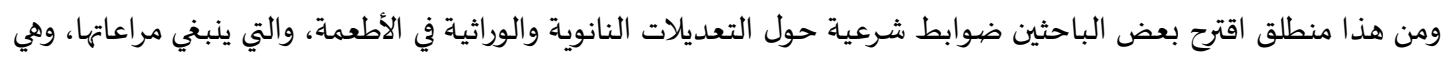

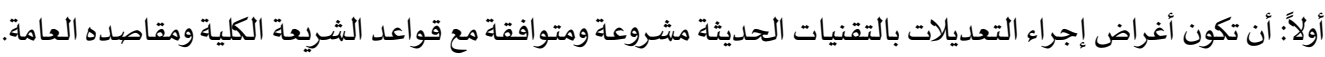

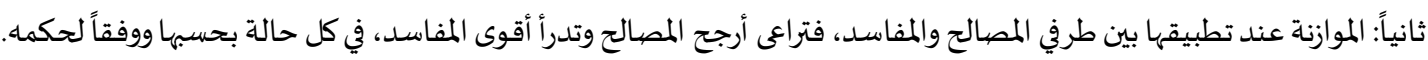

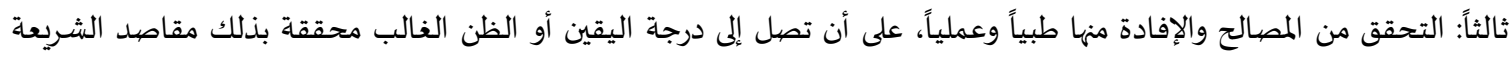

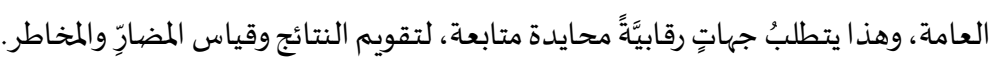

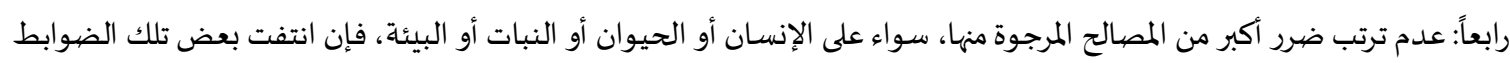

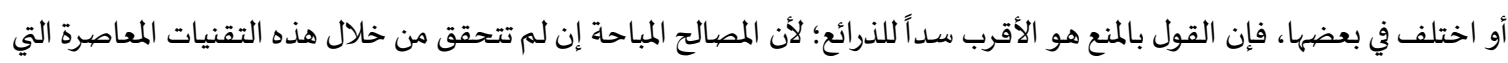
شرعت من أجلها فإنها ينقلب الحكم إلى المنع درأل للمفاسد المتوقعة، والله أعله.

المطلب الثاني: حكم تعاطي الأطعمة المعدلة بتنقية النانو تكنولوجي غذاءاً:

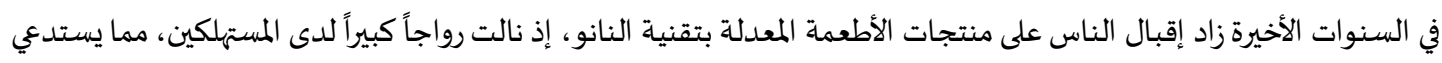

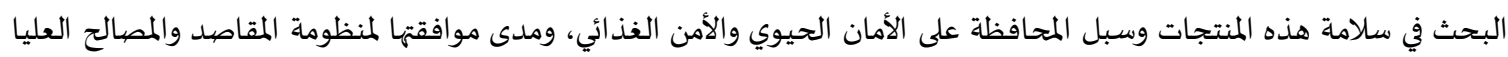

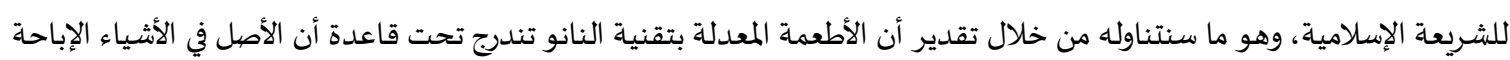

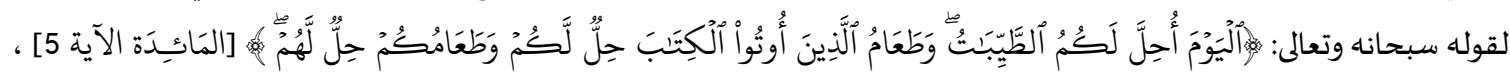

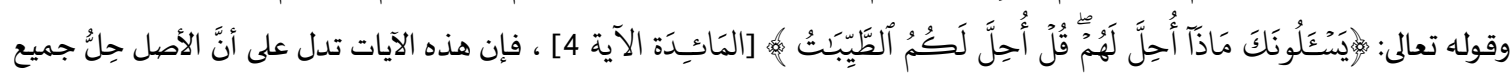

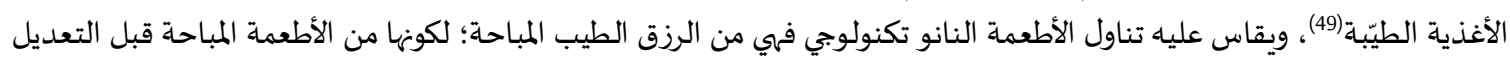

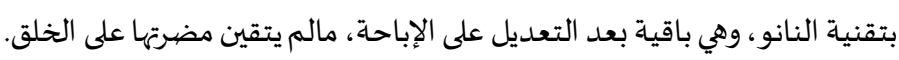

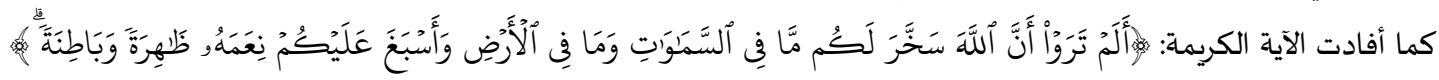

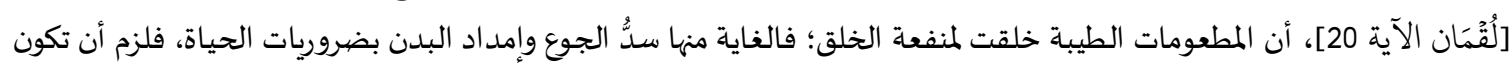
كافة الأطعمة مباحة ومن ضمنها الأطعمة النانوية (50). كما أن حديث أبى هريرة- رضى الله عنه- أنه قال: ( ما عاب رسول الله طعاماً قط، كان إذا إذا اشتهى شيئا أكله، وإذا كرهه تركه) (51)،

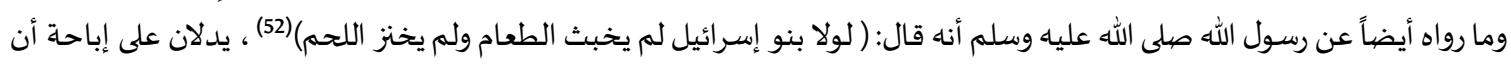

45 مجمع الفقه الإسلامي، العدد الرابع، (509/1). 46 ينظر: بسيوني، محمد شريف، الوثائق الدولية المعنية بحقوق الإنسان، (5005)، (2005)، (314/1)، (314/1). (37 المصدر السابق، (314/1).

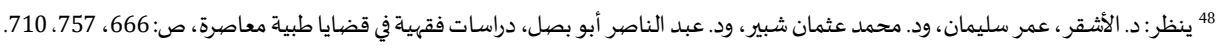

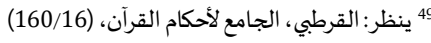

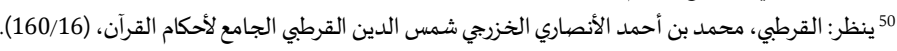

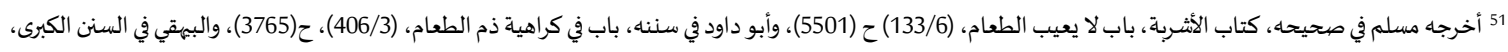

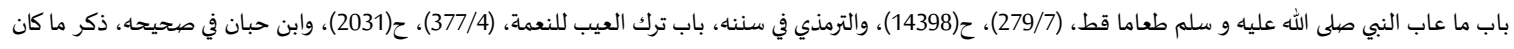

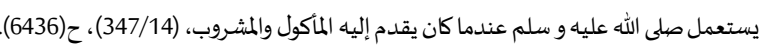


يأكل المسلم مما تشتهيه النفس من الأطعمة، مالم يكن محرماً، فالأصل أن كل الطعام النافع مباح، إلا ما حرم الله تعالى على بني

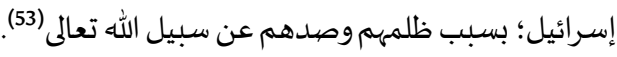
وفي إعمال قاعدة: (الأصل في الأشياء الإباحة حتى يدل الدليل على التحريم)(54) ما يؤكد على أن الأصل في الأعيان الطهارة، وإباحة

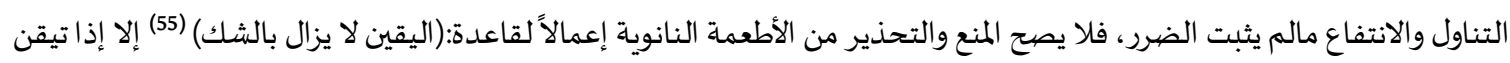

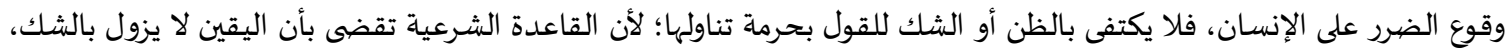

فتبقى على حكم الإباحة الأصلية (56).

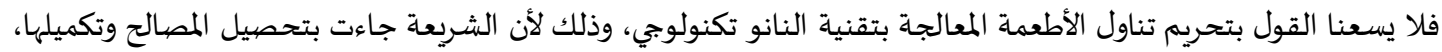

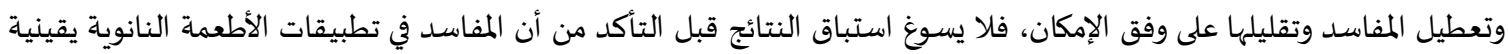
وغالبة لا يشوبها مصالح قد تساوي أو تغلب تلك المفاسد. وعلى تقدير ثبوت تلك المضار فلا يلزم القول بتحريم الأطعمة النانوية مطلقاً، وإنما لا بد من الموازنة بين المصالح والمفاسد، والنظر

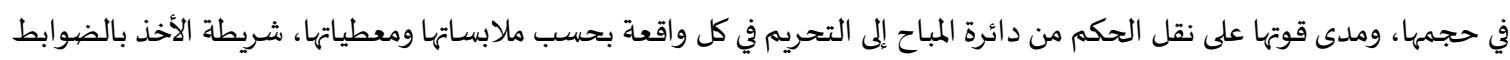

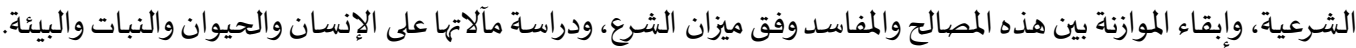

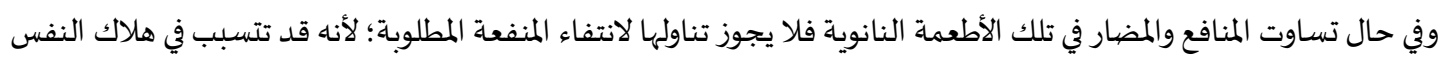

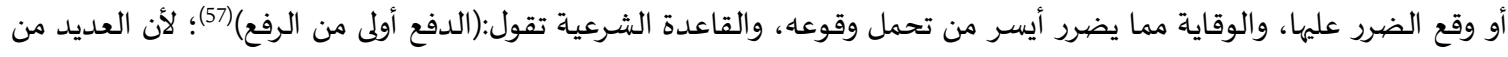

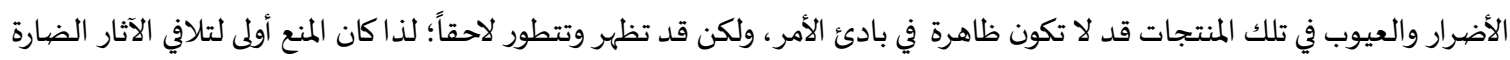

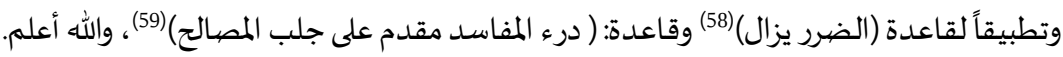

$$
\text { المطلب الثالث: حكم تعاطي الأطعمة النانو تكنولوجي للتداوي: }
$$

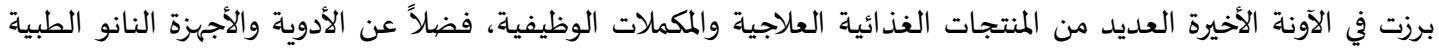

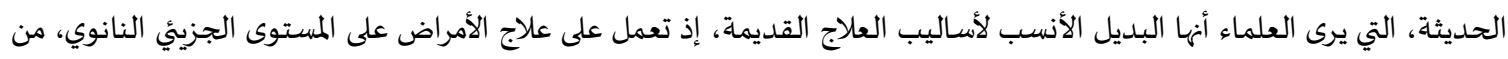

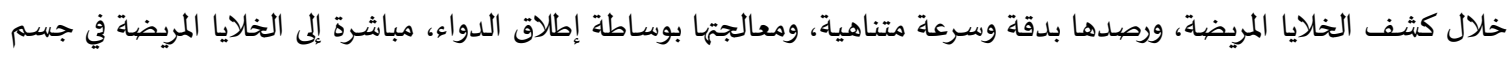

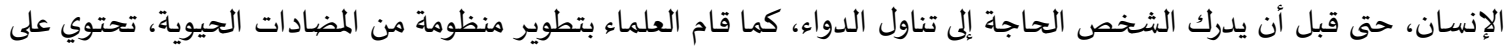

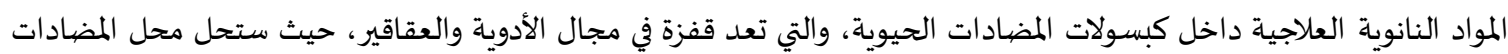
الحيوية التقليدية.

وإزاء هذه التطورات المتلاحقة في الأطعمة النانوية الوظيفية العلاجية، لابد من الوقوف على منافع الأغذية العلاجية النانوية

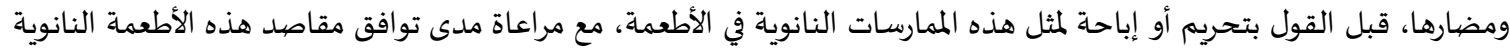

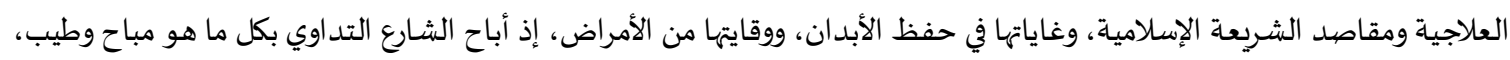

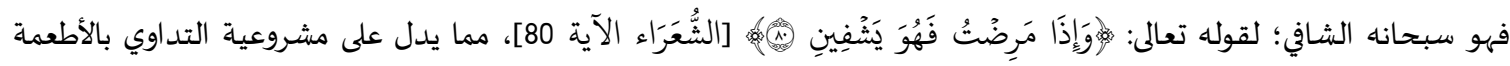

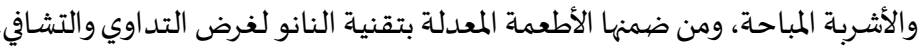

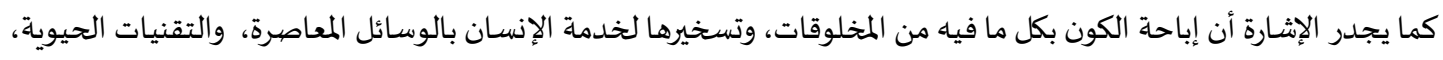

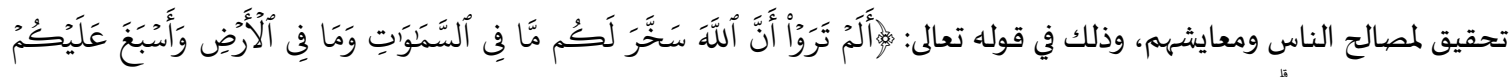

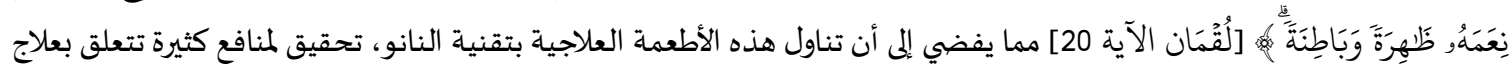
الأمراض المستعصية، وتطوير العقاقير الطبية.

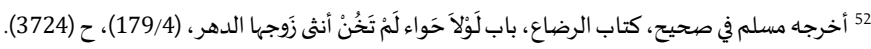

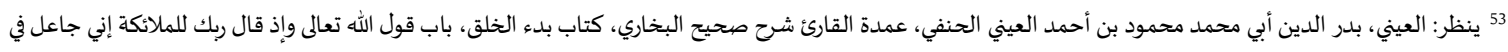

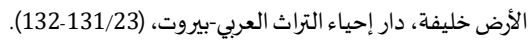

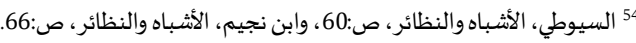

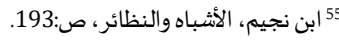

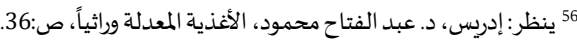
الم 57 السيوطي، الأشباه والنظائر، ص:138. (58 المصدر السابق، ص:83. (121/1) السبكي، الأشباه والنظائر، 


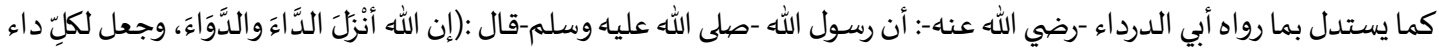

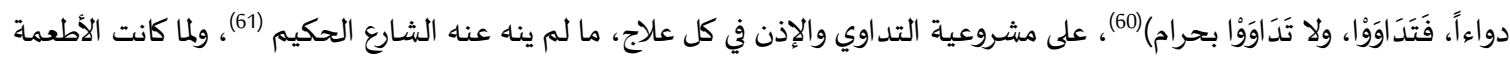

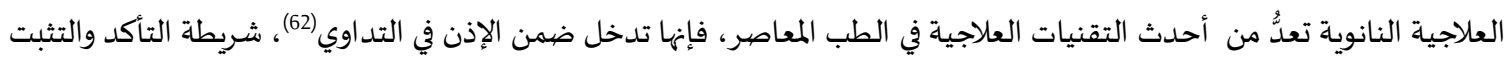

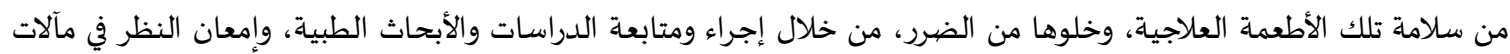

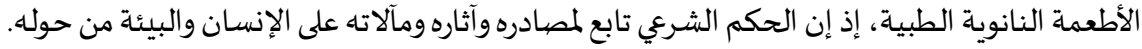

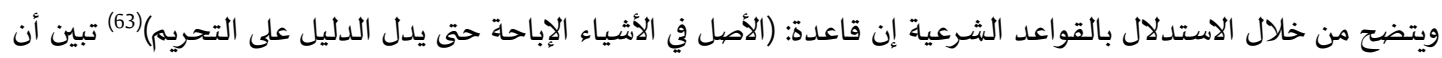

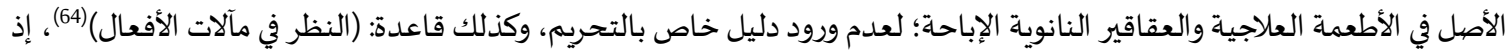

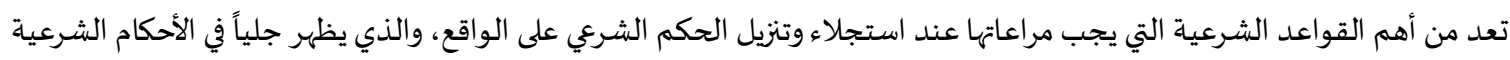

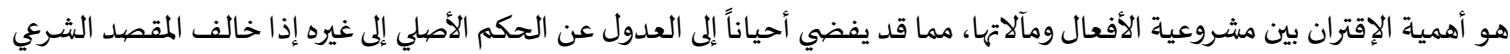

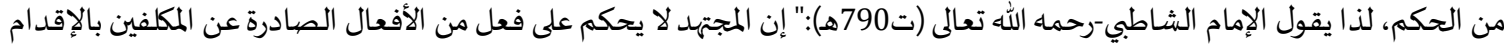

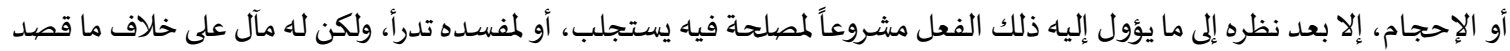

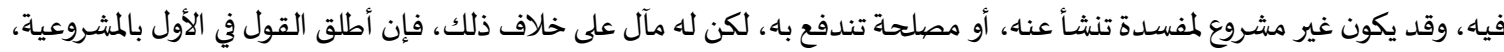

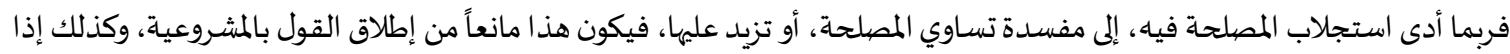

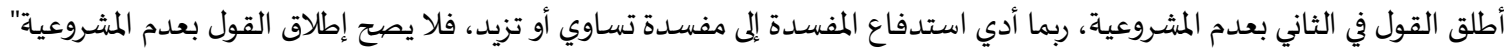

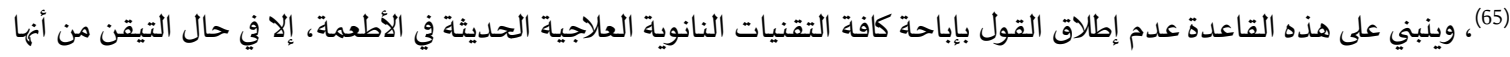

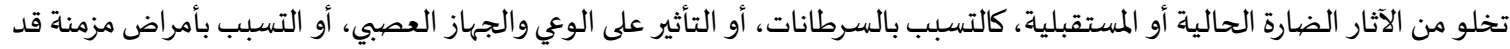

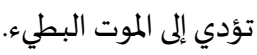
كما أن مقتضى إعمال قاعدة: (الضرر يزال) (66) في مشروعية استخدام الأطعمة والأدوية النانوية؛ لأغراض إزالة الضرر عن

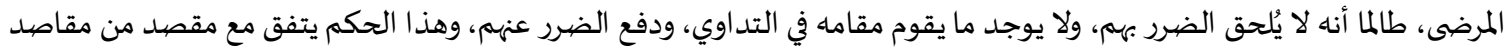

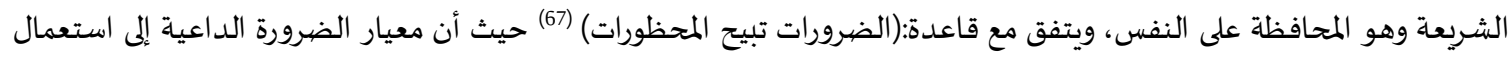

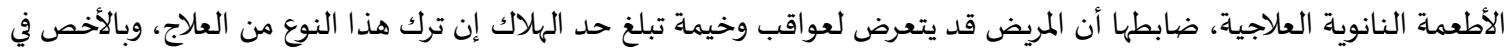

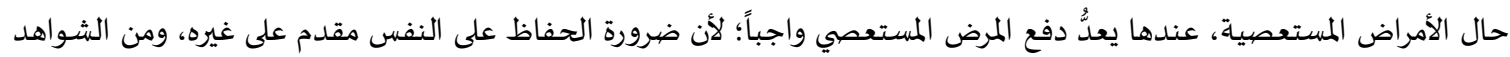

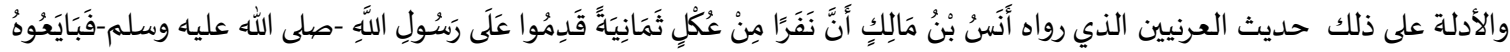

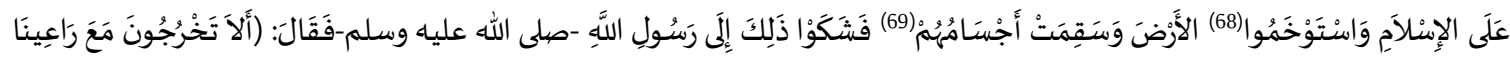

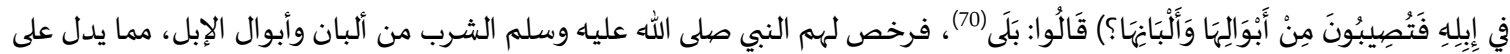

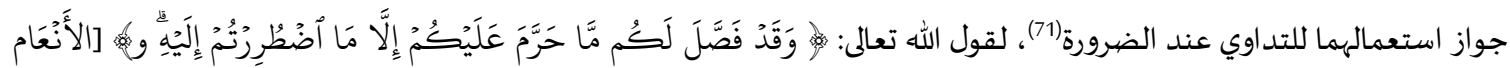

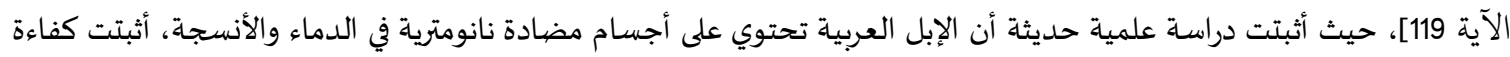

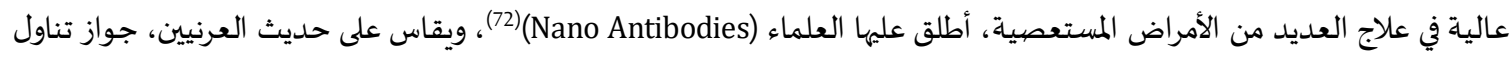

60 أخرجه أبو داود في سننه، في كتاب الطب، باب في الأدوبة المكروهة، (7/4)، ح (1412)، (3874)، والبهيقي في سننه، (5/10)، وذكره الهيثهي، نور الدين علي بن أبي بكر، في مجمع الزوائد ومنبع

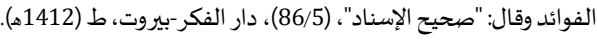

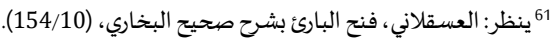

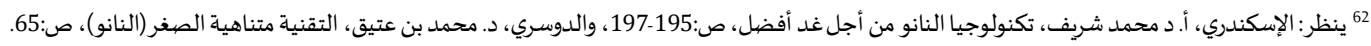

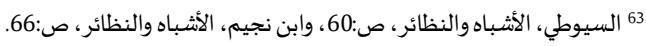

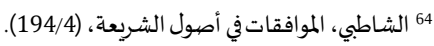
65 المصدر السابق، (25/4). 66 66 السيوطي، الأشباه والنظائر، ص:84. (67 المصدر السابق، ص:84.

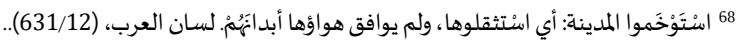

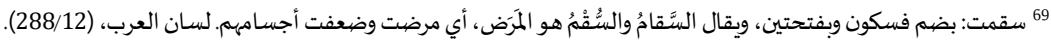

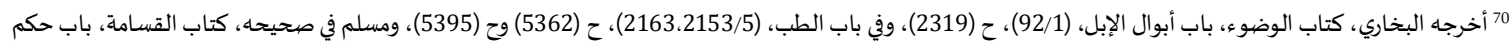

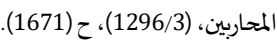

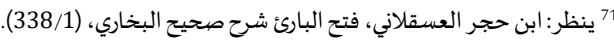

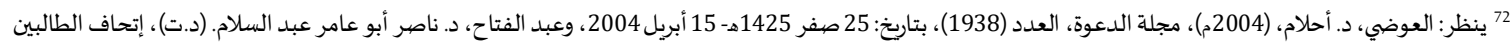
بشرح حديث العرنيين، ص:1510. المجلة الدولية للدراسات الإسلامية المتخصصة- المجلد6، العدد3- 2021، ص: 182- 197 
الأطعمة المصنّعة بتقنية الجزيئات النانوية الدوائية عند الضرورة(73)، إذا قرر أهل العلم والاختصاص نفعها، وأهها تحقق مصالح يقينية للمرضى، ولا تلحق الضرر بهم، ولا يوجد ما يقوم مقامه في التداوي، مع مراعاة أن تُستخدم في المجالات النافعة (الوقاية والتداوي).

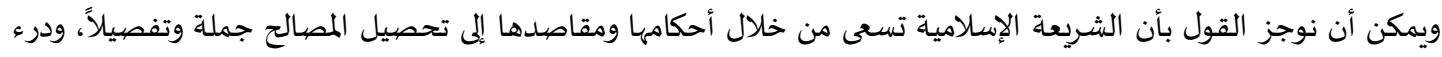

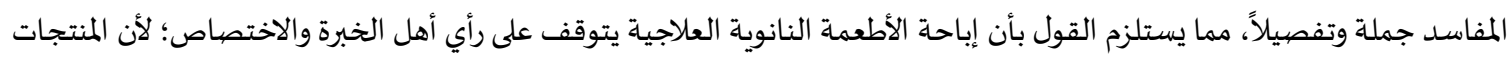
والتطبيقات النانوية العلاجية لم تخضع لتجارب عديدة وطويلة، ولم تتوافر الخبرة الكافية، والمعطيات الطبية الكافية التي تضمن سلامة لئه الاستخدام، أضف إلى ذلك قلة البحوث والدراسات التي تقارن بين الحالات المرضية قبل استعمال الأدوية والأغذية الوظيفية العلاجية وبعده(74). مما يستلزم وضع التدابير والمحاذير التي تحول دون العبث بالإنسان وطعامه ودوائه، مع الأخذ في الاعتبار السلبيات قبل

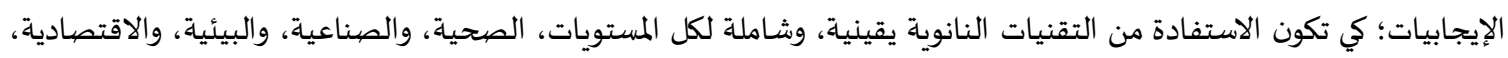
والله أجل وأعلم.

نتائج الدراسـة: بعد حمد الله جلّ وعلا وشكره على إعانته لنا في إكمال هذه الدراسة سائلين المولى التوفيق والسداد، نختم بأهم النتائج والتوصيات: أولاً: النتائج: فيما يأتي أهم النتائج التي توصلت الدراسـة إليها وهي كالآتي: • أن مفهوم علم النانوتكنولوجي هو الفهم والسيطرة على المواد في أبعاد ما يقرب من 1-100 نانو، ودراسة ابتكار تقنيات ووسائل جديدة تقاس أبعادها بالنانو متر. أن الأطعمة النانو تكنولوجي هي الأطعمة التي يتم إعدادها أو معالجتها، في أية مرحلة من مراحل إنتاجها المختلفة، المتعلقة بزراعتها

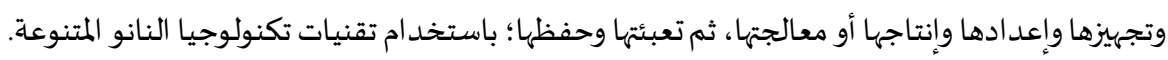
أن تعلم العلوم المعاصرة والتقنيات الحديثة كعلم النانو تكنولوجي يعدُّواجباً كفائياً على الأمة الإسلامية. أن الأطعمة المعدلة بالنانو تكنولوجي لم تعد أطعمة طبيعية بسبب تغير حقيقتها الفطرية؛ إذ تعدّ دخيلة على سلسلة الأطعمة الطبيعية، وبسبب هذه المفارقة، فإن إجراء كافة أحكام الأطعمة الشرعية عليها، يحتاج نظراً عميقاً في ماهيتها. أن حكم تعاطي الأطعمة المعدلة بالنانو تكنولوجي غذاءًا أو داوءاً يتوقف على النظر الفقهي في حجم المفاسد التي تؤول إلهها هذه

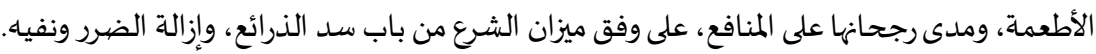
إباحة استعمال الأطعمة النانوية العلاجية والعقاقير الطبية، يعتمد على تقدير أهل العلم والاختصاص، وحاجة المرضىى وإنى

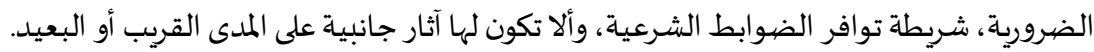
ثانياً: التوصيات:

إجراء المزيد من الأبحاث العلمية والشرعية حول الأحكام الشرعية الخاصة باستخدامات النانو تكنولوجي في مجالات الحياة المختلفة. هقد المؤتمرات والورش والندوات لدراسة المستجدات الشرعية حول هذه التقانة الحيوية في مجال الإنتاج والتصنيع الزراعي. وآخر دعوانا أن الحمد لله رب العالمين في الأولى والآخرة، وصلى الله وسلم وبارك على سيدنا محمد وعلى آله وصحبه وسلم. 


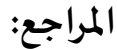

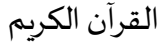

1. إدريس، عبد الفتاح (1427ه). دراسات شرعية حول الأغذية المعدلة وراثياً من منظور إسلامي. مجلة الجندي المسلم. السنة

السادسة والثلاثون، العدد (126).

2. إدريس، عبد الفتاح محمود (2010). الأغذية المعدلة وراثياً. مجلة الوعي الإسلامي، العدد:

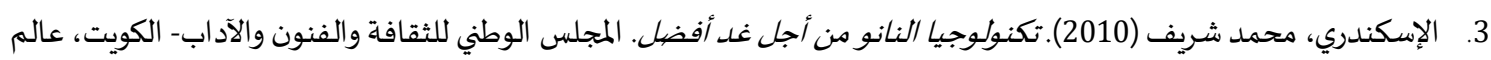

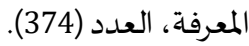

4. الأشقر، عمر سليمان، ود. محمد عثمان شبير، ود. عبد الناصر أبو بصل (2001). دراسات فقهية في قضايا طبية معاصرة. ط1،

دار النفائس-الأردن.

5. بري، محمود (2011). النانو تكنولوجي وعود كبيرةومخاطر كبيزة. ط1، مؤسسة الفكر العربي للبحوث والدراسات-سلسلة معارف

تصبدرها مؤسسة الفكر العربي-ييروت.

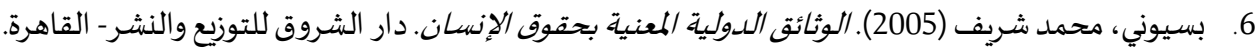

7. تشالا إس.إس.آر. كومار، ودوزيف هورميس وآخرون (2013). التصنيع النانوي الموجّه للتطبيقات الطبية الحيوية (التقنيات-

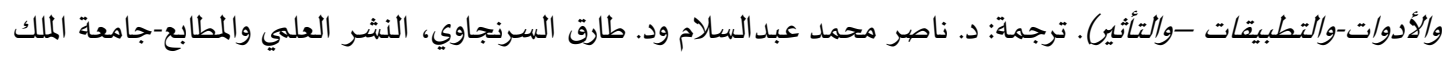

سعود.

8. جمعية العلوم الطبية الإسلامية الأردنية (1415ه).قضايا طبية معاصرة في ضوء الشريعة الإسلامية. ط1، دار البشير-عمان.

9.

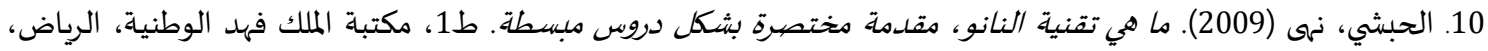

السعودية السبان

11. الحوشاني، شريفة بنت علي بن سليمان (2012). فقه التوقع ومآلات تقنية النانو. مجلة مكرز البحوث والدراسات الإسلامية،

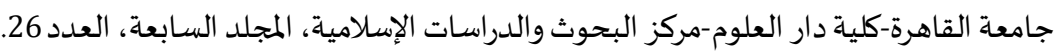

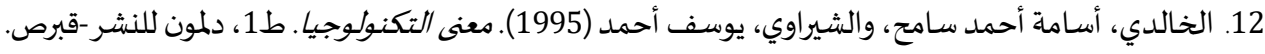

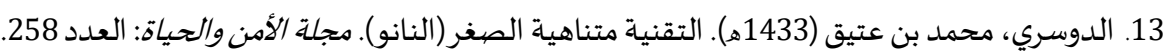

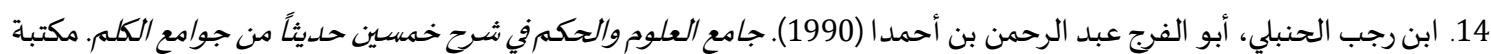

الإيمان-دمشق.

15. سالم، منير محمد (د.ت). طب النانو (الآفاق والمخاطر). مجلة عجمان للمدراسات والبحوث: المجلد العاشر، العدان العدان الأول

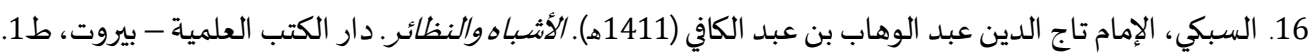

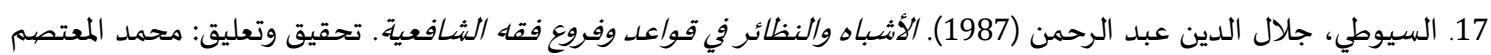

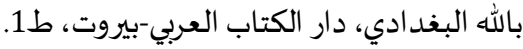

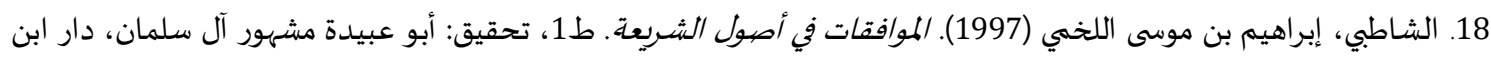

عفان-الخبر، السعودية.

19. الشريف، ولاء محمود علي أحمد (2015). النانو تكنولوجي في مجال صناعة الغذاء. مجلة أسيوط للدراسات البيئية: العدد الثاني

والأربعون.

20. الشويرخ، سعد بن عبد الله الشويخ (2007). أحكام الهندسة الوراثية. كنوز إشبيليا للنشر والتوزيع-الرياض، ط1.

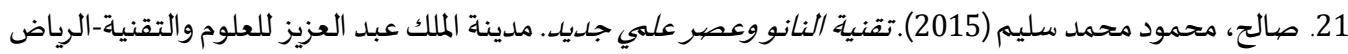

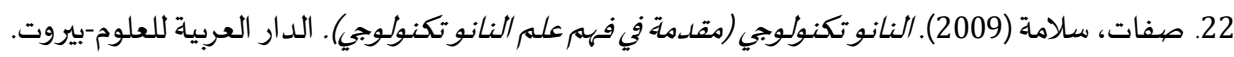

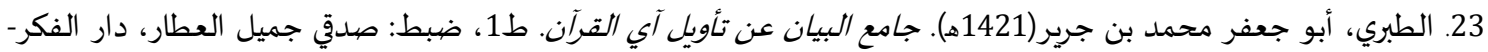

بيروت.

24. الطعيمات، هاني سليمان محمد (2012). تكنولوجيا النانو من وجهة نظر شرعية. وزارة الأوقاف والشئون الإسلامية، مجلد56،

العدد 8، تشرين الأول-ذو القعدة. 
25. عبد الحميد، عفاف السيد بدوي (2017). استخدام تكنولوجيا النانو في إعادة تدوير المخلفات الزراعية وأثره على تخفيض

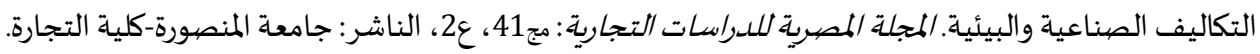
26. عبد الفتاح، ناصر أبو عامر عبد السلام (د.ت). إتحاف الطالبين بشرح حديث العرنيين. مجلة كلية الدراسات الإسلامية: العدد العادية الرابع والثلاثون.

27. العز بن عبد السلام، أبو محمد عز الدين عبد العزيز السلهي الدمشقي (د.ت). قواعد الأحكام في مصالح الأنام. تحقيق: محمود بن التلاميد الشنقيطي، دار المعارف بيروت. 28. أبو عساف، إسماعيل (2005). أساسيات بيولوجيا الخلية والهندسة الوراثية وعلم الجنين. دارئ المار الأهلية للنشر والتوزيع.

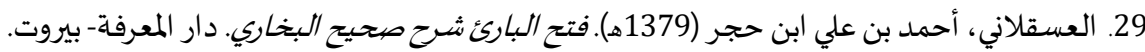

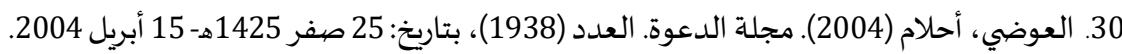

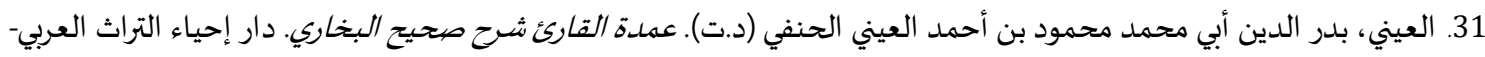
بيروت.

32. القرافي، أبو العباس أحمد بن إدربس الصنهاجي (1998). الفروق، تحقيق: خليل المنصيور، دار الكتب العلمية -بيروت.

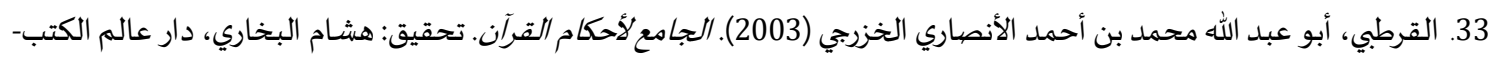
الرياض.

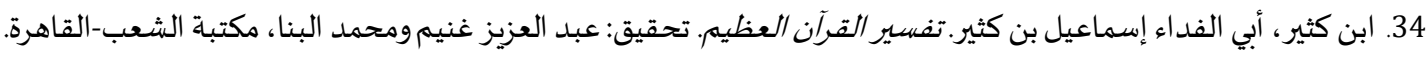

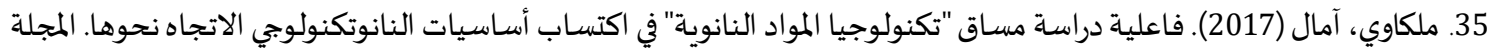

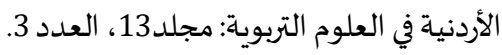

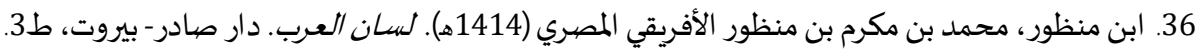

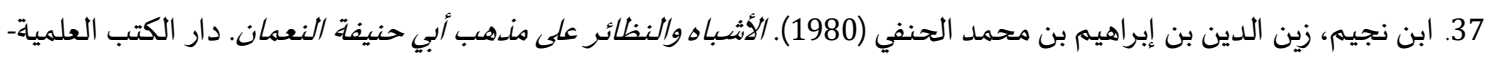




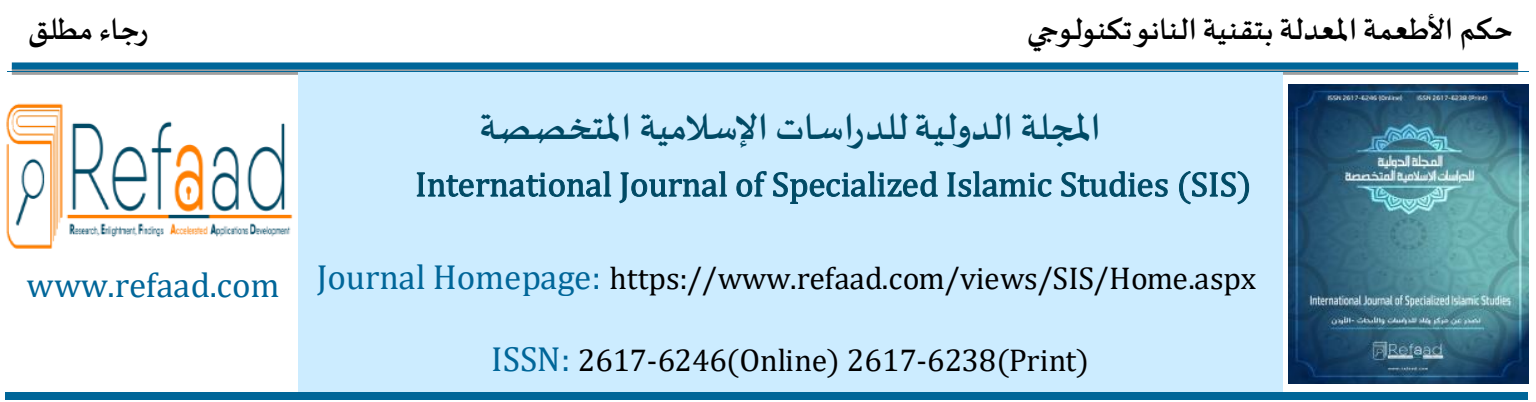

\title{
Ruling of Nanotechnology modified foods
}

\author{
Raja Mohammad Mahfoodh Mutleq \\ Assistant Professor, Seiyun University, Yemen \\ dr.motlaq3@gmail.com
}

Received: 6/10/2021 Revised: 20/10/2021 Accepted: 7/11/2021 DOI: https://doi.org/10.31559/SIS2021.6.3.3

Abstract: The study deals with foods processed with nanotechnology, which is one of the catastrophes that lack a statement of the position of Islamic law. Nano-modified foods are foods in which the arrangement of the atoms and nanometric molecules that make them up were controlled by nanotechnology to obtain modern foods with exact specifications. The researcher relied in this study on the inductive method. The descriptive analytical method was used to prepare a jurisprudential study that formulates jurisprudential rulings for each specific incident in the food crisis with nanotechnology in accordance with the principles of the general Sharia in order to acknowledge its purposes, its universal rules, and its comprehensive controls, which contribute to alleviating embarrassment and bringing significant interests, repelling corruption, and achieving the lofty goals of Islamic law. The study was concluded with some results among which are: that nano-modified foods are no longer natural foods due to the change in their innate reality as they are considered an alien to the natural food chain. Because of this paradox, the jurist cannot implement all the provisions of legal foods on them, and that leaves the use of nano-modified foods as foods or medicines that should depend on the jurisprudential consideration of the extent of the negative effects that these foods lead to, the extent of their preponderance over the benefits according to the balance of Sharia in terms of blocking excuses, and that pushing away is a priority to pushing up.

Keywords: food ruling; nanotechnology; nano-modified foods.

\section{References:}

- Alqran Alkrym

1. 'bd Alftah, Nasr Abw 'amr 'bd Alslam (D.T). Ethaf Altalbyn Bshrh Hdyth Al'rnyyn. Mjlt Klyt Aldrasat Aleslamyh: Al'dd Alrab' Walthlathwn.

2. 'bd Alhmyd, 'faf Alsyd Bdwy (2017). Astkhdam Tknwlwjya Alnanw Fy E'adh Tdwyr Almkhlfat Alzra'yh Wathrh 'la Tkhfyd Altkalyf Alsna'yh Walby'yh. Almjlh Almsryh Lldrasat Altjaryh: Mj41, '2, Alnashr: Jam'eh Almnswrh-Klyh Altjarh.

3. Abw 'saf, Esma'yl (2005). Asasyat Bywlwjya Alkhlyh Walhndsh Alwrathyh W'lm Aljnyn. Dar Alahlyh Llnshr Waltwzy'.

4. Al'sqlany, Ahmd Bn 'ly Abn Hjr (1379h). Fth Albar' Shrh Shyh Albkhary. Dar Alm'rfh- Byrwt.

5. Al'z Bn 'bd Alslam, Abw Mhmd 'z Aldyn 'bd Al'zyz Alslmy Aldmshqy (D.T). Qwa'ed Alahkam Fy Msalt Alanam. Thqyq: Mhmwd Bn Altlamyd Alshnqyty, Dar Alm'arf Byrwt.

6. Al'wdy, Ahlam (2004). Mjlt Ald'wh. Al'dd (1938), Btarykh: 25 Sfr 1425h- 15 Abryl 2004.

7. Alashqr, 'mr Slyman, Wd. Mhmd 'thman Shbyr, Wd. 'bd Alnasr Abw Bsl (2001). Drasat Fqhyh Fy Qdaya Tbyh M'asrh. T1, Dar Alnfa's-Alardn.

8. Bry, Mhmwd (2011). Alnanw Tknwlwjy W'wd Kbyrh Wmkhatr Kbyrh. T1, M'sst Alfkr Llbhwth WaldrasatSlslt M'arf Tsdrha M'sst Alfkr Al'rby-Byrwt.

9. Bsywny, Mhmd Shryf (2005). Alwtha'q Aldwlyh Alm'nyh Bhqwq Alensan. Dar Alshrwq Lltwzy' WalnshrAlqahrh.

10. Aldwsry, Mhmd Bn 'tyq (1433h). Altqnyh Mtnahyh Alsghr (Alnanw). Mjlt Alamn Walhyah: Al'dd 258. 
11. Edrys, 'bd Alftah (1427h). Drasat Shr'yh Hwl Alaghdyh Alm'edlh Wrathyaan Mn Mnzwr Eslamy. Mjlt Aljndy Almslm. Alsnh Alsadsh Walthlathwn, Al'dd (126).

12. Edrys, 'bd Alftah Mhmwd (2010). Alaghdyh Alm'dlh Wrathyaan. Mjlt Alw'y Aleslamy, Al'dd: 532.

13. Aleskndry, Mhmd Shryf (2010). Tknwlwjya Alnanw Mn Ajl Ghd Afdl. Almjls Alwtny Llthqafh Walfnwn Waladab- Alkwyt, 'alm Alm'rfh, Al'dd (374).

14. Alharthy, Bdryh Msh'l (2011). Alnwazl Fy Alat'mh. Dar Knwz Eshbylyh-Alryad, T1.

15. Alhbshy, Nha (2009). Ma Hy Tqnyt Alnanw, Mqdmh Mkhtsrh Bshkl Drws Mbsth. T1, Mktbt Almlk Fhd Alwtnyh, Alryad, Als'wdyh

16. Alhwshany, Shryfh Bnt 'ly Bn Slyman (2012). Fqh Altwq' Wmalat Tqnyh Alnanw. Mjlt Mrkz Albhwth Waldrasat Aleslamyh, Jam't Alqahrh-Klyt Dar Al'lwm-Mrkz Albhwth Waldrasat Aleslamyh, Almjld Alsab'h, Al'dd 26.

17. Jm'yt Al'lwm Altbyh Aleslamyh Alardnyh (1415h). Qdaya Tbyh M'asrh Fy Dw' Alshry'h Aleslamyh. T1, Dar Albshyr-'man.

18. Alkhaldy, Asamh Ahmd Samh, Walshyrawy, Ywsf Ahmd (1995). M'na Altknwlwjya. T1, Dlmwn Llnshr-Qbrs.

19. Abn Rjb Alhnbly, Abw Alfrj 'bd Alrhmn Bn Ahmda (1990). Jam' Al'lwm Walhkm Fy Shrh Khmsyn Hdythaan Mn Jwam' Alklm. Mktbt Aleyman-Dmshq.

20. Salh, Mhmwd Mhmd Slym (2015). Tqnyt Alnanw W'sr 'my Jdyd. Mdynh Almlk 'bd Al'zyz Ll'lwm WaltqnyhAlryad.

21. Salm, Mnyr Mhmd (D.T). Tb Alnanw (Alafaq Walmkhatr). Mjlt 'jman Lldrasat Walbhwth: Almjld Al'ashr, Al'dd Alawl

22. Alsbky, Alemam Taj Aldyn 'bd Alwhab Bn 'bd Alkafy (1411h). Alashbah Walnza'r. Dar Alktb Al'lmyh - Byrwt, T1.

23. Sfat, Slamh (2009). Alnanw Tknwlwjy (Mqdmh Fy Fhm 'Im Alnanw Tknwlwjy). Aldar Al'erbyh Ll'elwmByrwt.

24. Alshatby, Ebrahym Bn Mwsa Allkhmy (1997). Almwafqat Fy Aswl Alshry'h. T1, Thqyq: Abw 'bydh Mshhwr Al Slman, Dar Abn 'fan-Alkhbr, Als'wdyh.

25. Alshryf, Wla' Mhmwd 'ly Ahmd (2015). Alnanw Tknwlwjy Fy Mjal Sna't Alghda'. Mjlt Asywt Lldrasat Alby'yh: Al'dd Althany Walarb'wn.

26. Alshwyrkh, S'd Bn 'bd Allh Alshwyrkh (2007). Ahkam Alhndsh Alwrathyh. Knwz Eshbylya Llnshr Waltwzy'Alryad, T1.

27. Alsywty, Jlal Aldyn 'bd Alrhmn (1987). Alashbah Walnza'r Fy Qwa'd Wfrw' Fqh Alshaf'yh. Thqyq Wt'lyq: Mhmd Alm'tsm Ballh Albghdady, Dar Alktab Al'rby-Byrwt, T1.

28. Alt'ymat, Hany Slyman Mhmd (2012). Tknwlwjya Alnanw Mn Wjht Nzr Shr'yh. Wzart Alawqaf Walsh'wn Aleslamyh, Mjld 56, Al'dd 8, Tshryn Alawl-Dw Alq'dh.

29. Altbry, Abw J'fr Mhmd Bn Jryr(1421h). Jam' Albyan 'n Tawyl Ay Alqran. T1, Dbt: Sdqy Jmyl Al'tar, Dar AlfkrByrwt.

30. Tshala Es.Es.Ar. Kwmar, Wdwzyf Hwrmys Wakhrwn (2013). Altsny' Alnanwy Almwjh Llttbyqat Altbyh Alhywyh (Altqnyat-Waladwat-Walttbyqat -Waltathyr). Trjmt: D. Nasr Mhmd 'bdalslam Wd. Tarq Alsrnjawy, Alnshr Al'lmy Walmtab'-Jam't Almlk S'wd. 